Doi: https://doi.org/10.47879/ed.ep.2020018

\title{
ST) UNICAMA
}

UNIGAMA CENTRO UNIVERSITÁRIO

TRABALHO DE CONCLUSÃO DO CURSO DE ARQUITETURA E URBANISMO

ETAPA DE PROJETO

ALUNA: RENATA SANTOS LYRA

MAT. 19140139

ORIENTADOR: PROFESSOR MILTON BANDEIRA SAMPAIO

COORDENADOR DE CURSO: PROFESSOR BRUNO MATOS FARIAS

CONVIDADA: PROFESSORA LIANE FLEMMING 
O Transtorno do Espectro Autista, ou TEA, é uma alteração do neurodesenvolvimento caracterizada por déficit na comunicação social e comportamental.

Seus pensamentos são rígidos, apresentando dificuldade de flexibilização, assim quando querem alguma coisa tem maior dificuldade em mudar de pensamento, o que pode gerar reações mais emotivas ou comportamentos desajustados com maior excitação e dificuldade ao retorno ao foco as atividades.

Segundo a Organização das Nações Unidas (ONU), afeta em média 70 milhões de pessoas em todo o mundo.

Autistas e suas famílias precisam de suporte, cuidados multidisciplinares e orientação para conquista de seus direitos.

Autistas adultos são muitas vezes excluídos e esquecidos ou ignorados pela sociedade. 


\section{OBJETIVOS DO PROJETO:}

Disponibilizar espaço para conscientização pública sobre o Transtorno do Espectro Autista, em eventos a serem realizados no auditório, além de incentivar o comércio local a inserir em seu quadro, profissionais capacitados pelo Centro.

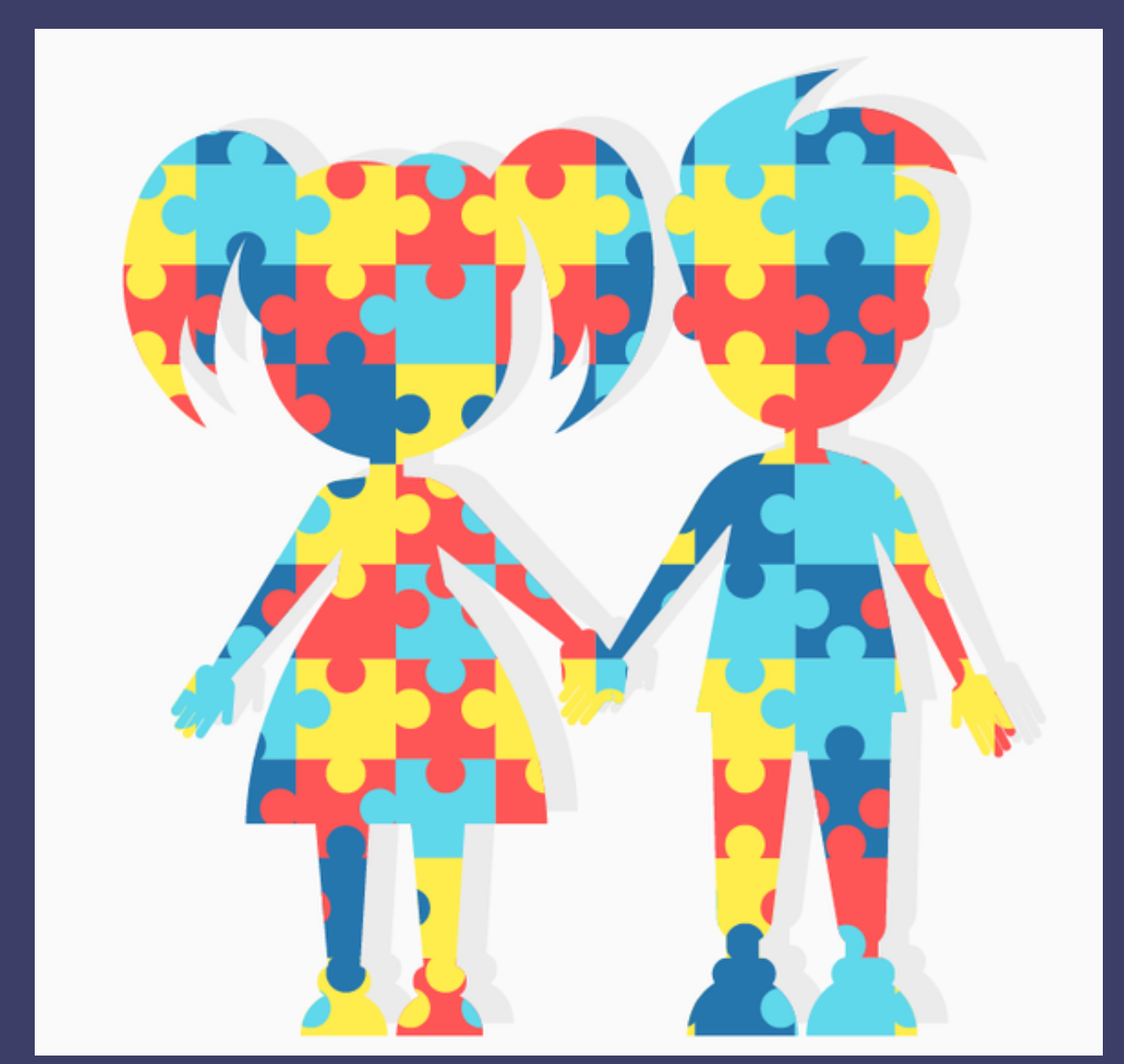

02

Capacitar jovens e adultos para atuação no mercado de trabalho.

03

Permitir o deslocamento dentro do Centro de maneira independente através da Acessibilidade cognitiva, tendo como pontos chave a objetividade e clareza nas informações.

04 Propiciar um ambiente acessível, estimulante e humanizado para usuários e profissionais. 


\section{MOTIVO E INSPIRAÇÃO:}

GUSTAVO RIBEIRO LYRA, O GUGA
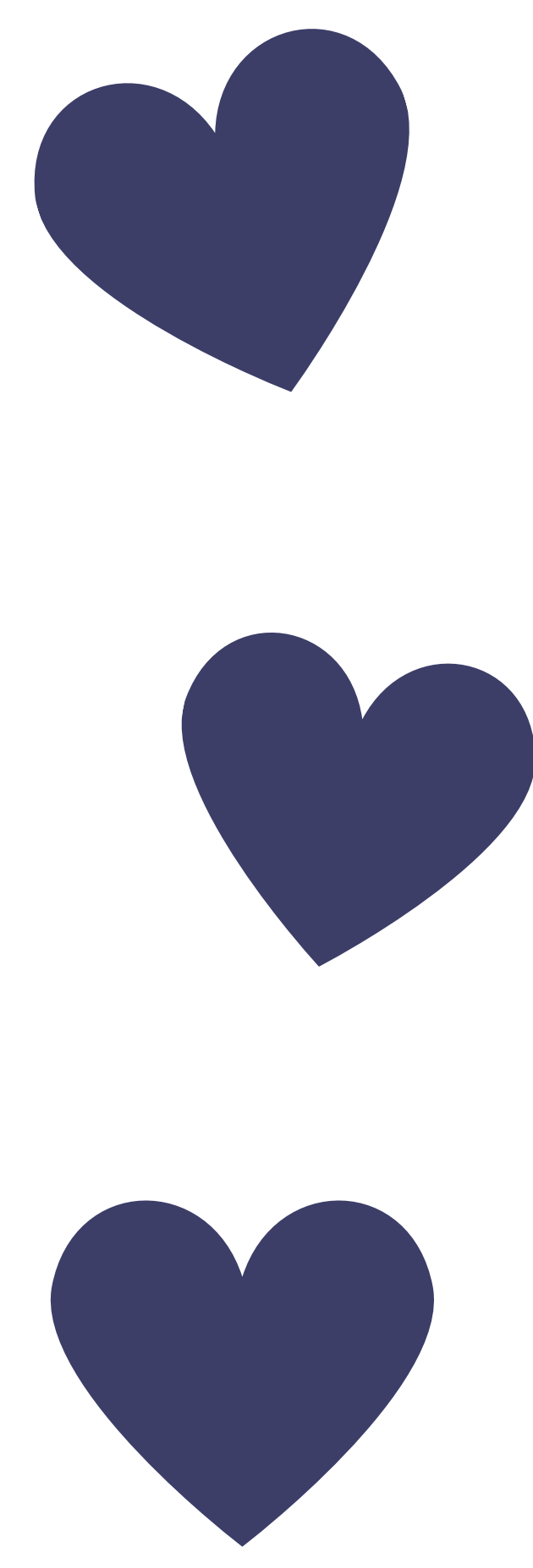

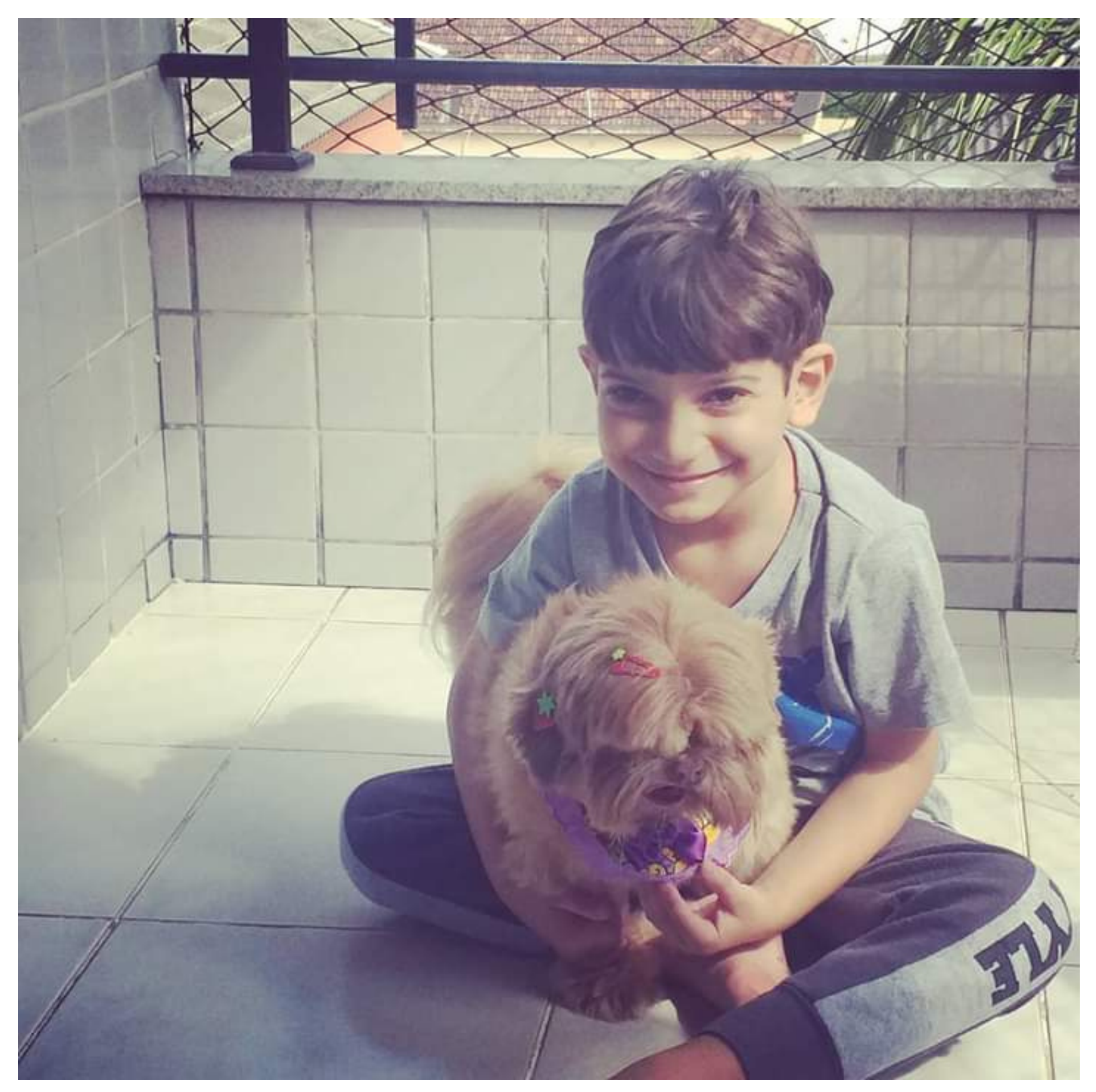

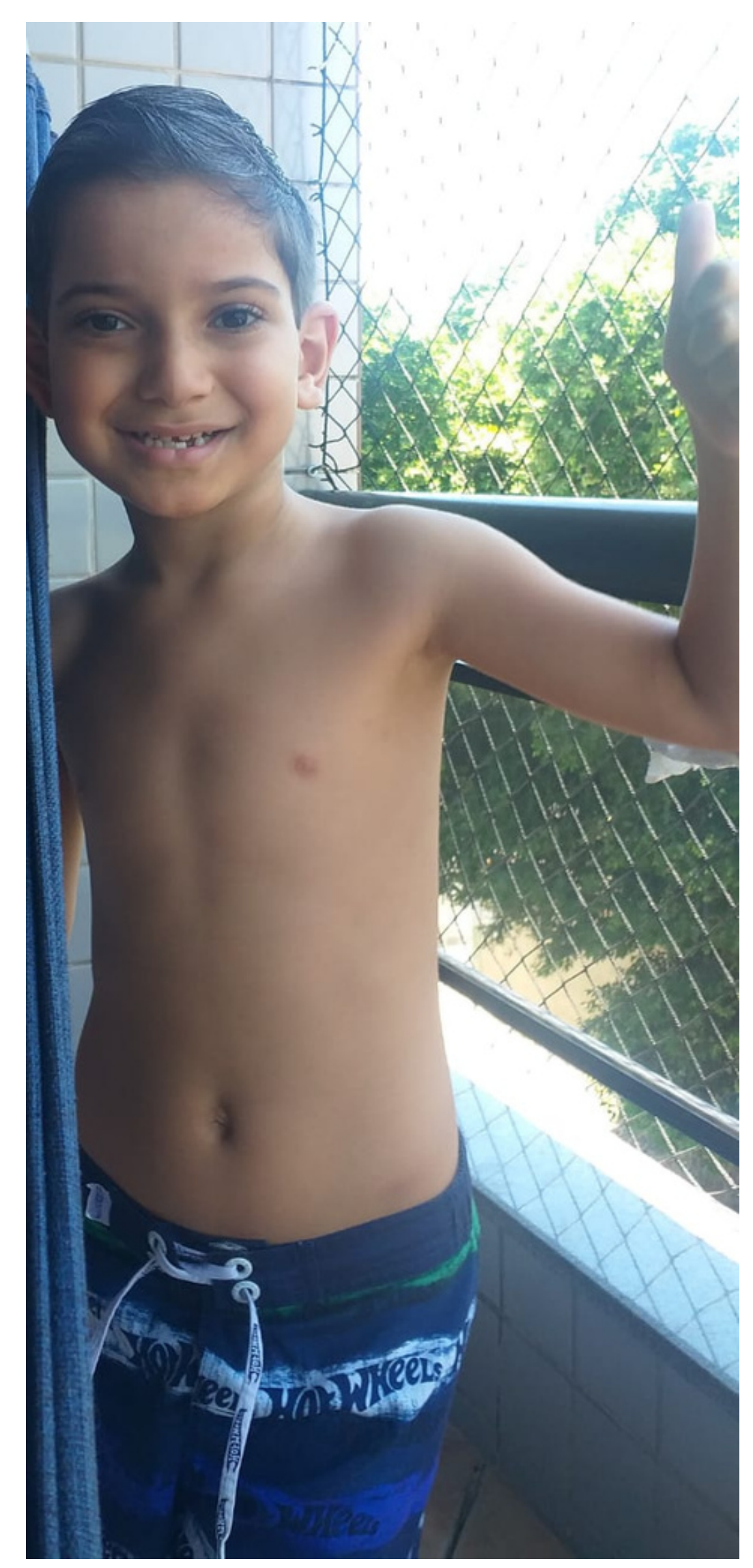


CONCEITO

PARTIDO
QUEBRA-CABEÇAS - símbolo do autismo

Usado pela primeira vez pela Autism Speaks. Define a complexidade da compreensão do pensamento autista.

\section{5 autism}

Proporcionar um local com total acessibilidade física e cognitiva, através da arquitetura humanizada aliada à possibilidade de rápida construção e reprodução, com o custo reduzido da arquitetura modular, utilizando como recurso as placas pré moldadas de poliestireno expandido. 


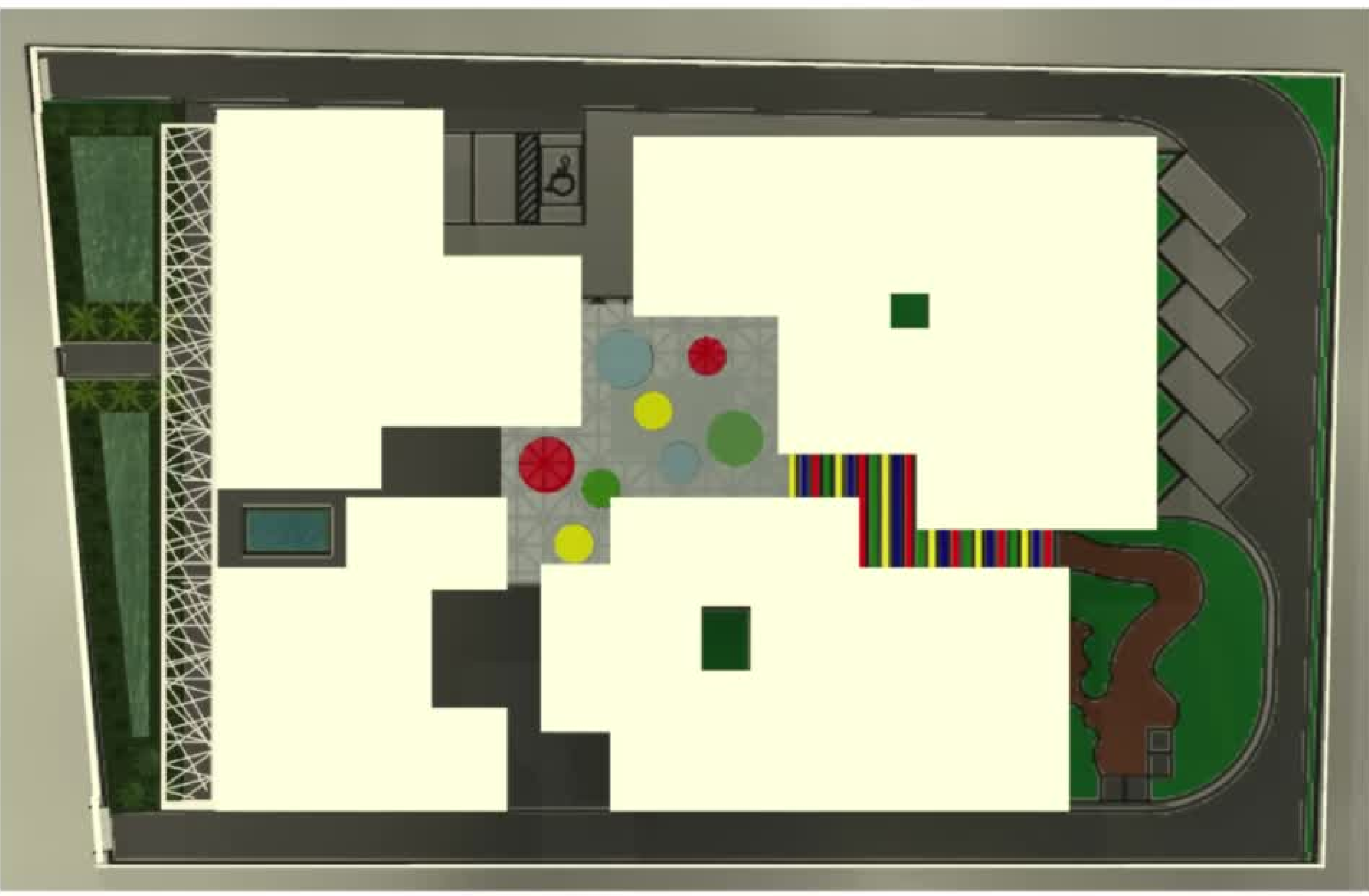




\section{MODULAÇÃO}

Recurso utilizado na proporcionalidade das medidas de cada bloco, concluindo o efeito de encaixe.

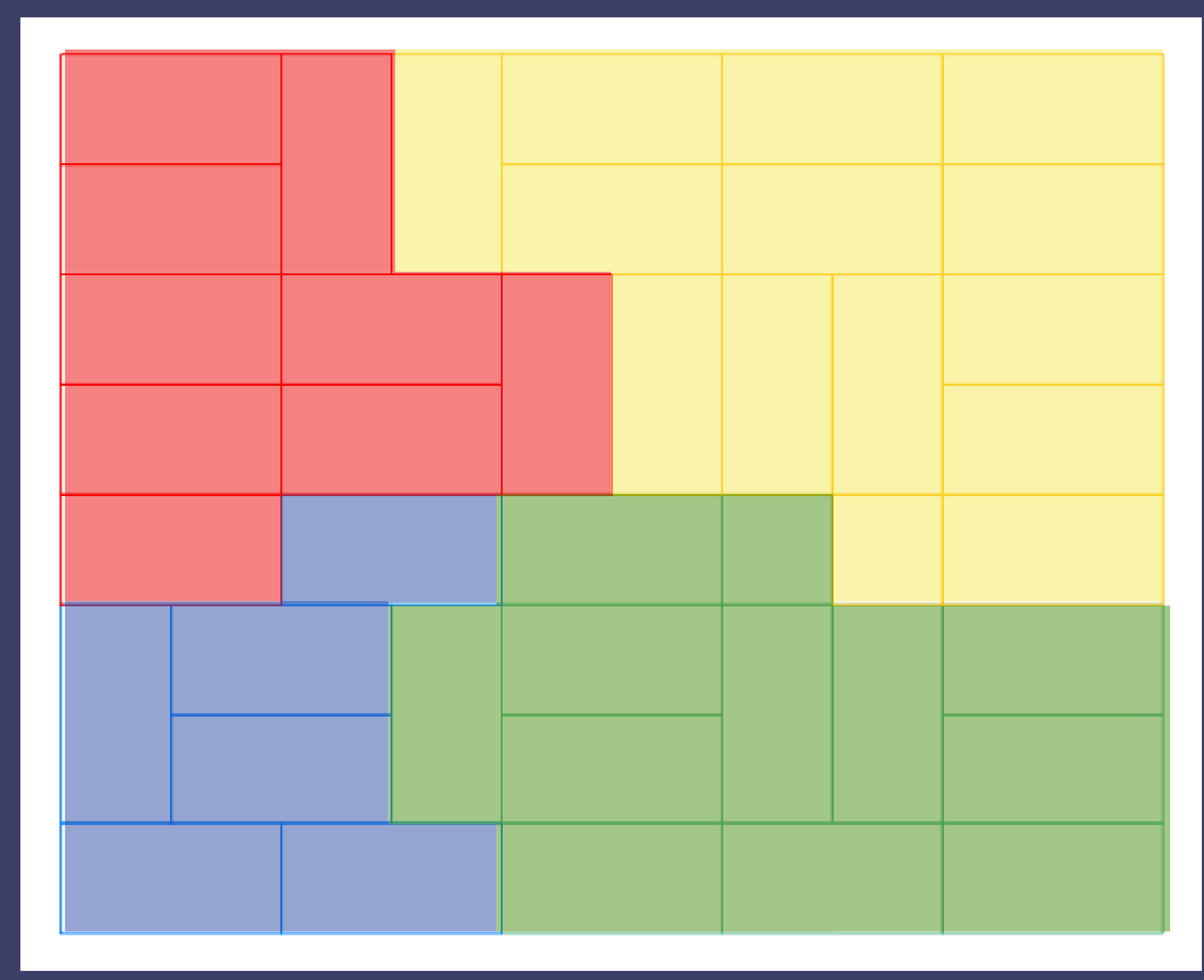




\section{ORGANIZAÇÃO}

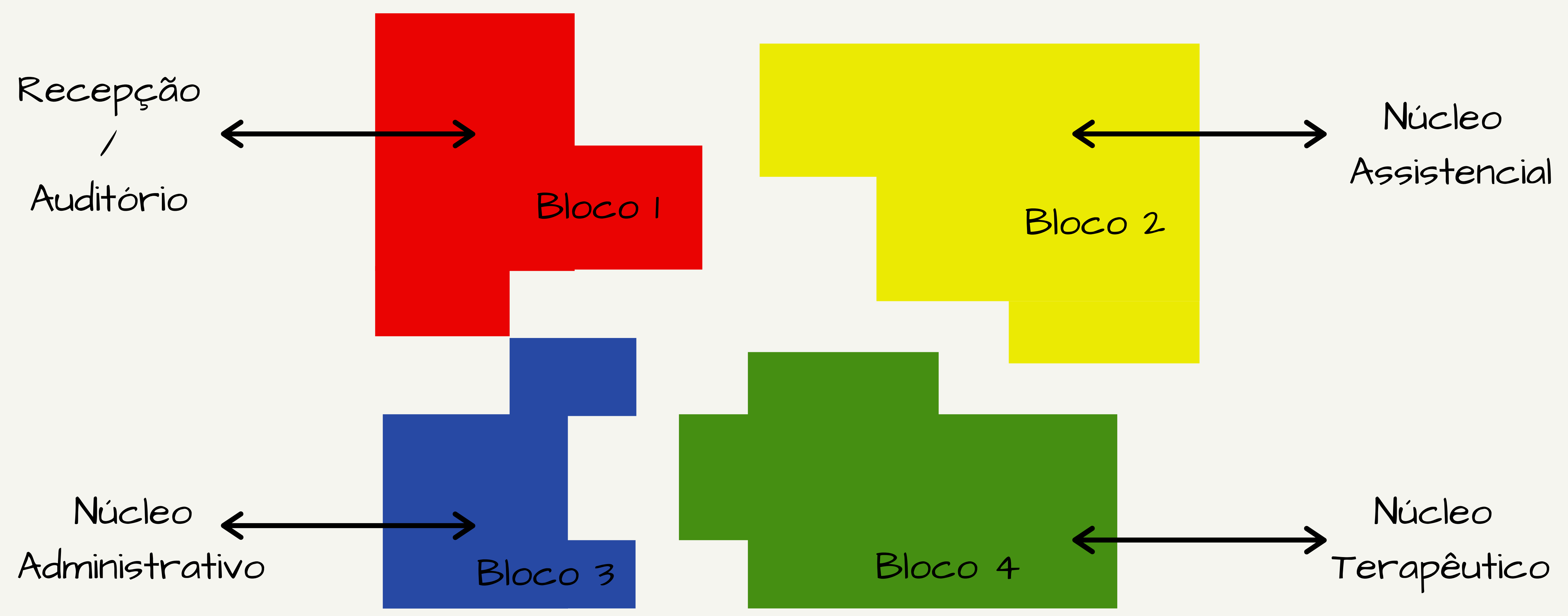


PROGRAMA DE NECESSIDADES:
Acesso Principal

Jardins / Área Comum externa

Salas de Espert

Auditório

úcleo de atendimento psicológico

Núcleo de orientação jurídica

Dispensa 


\section{SETORIZAÇÃO}

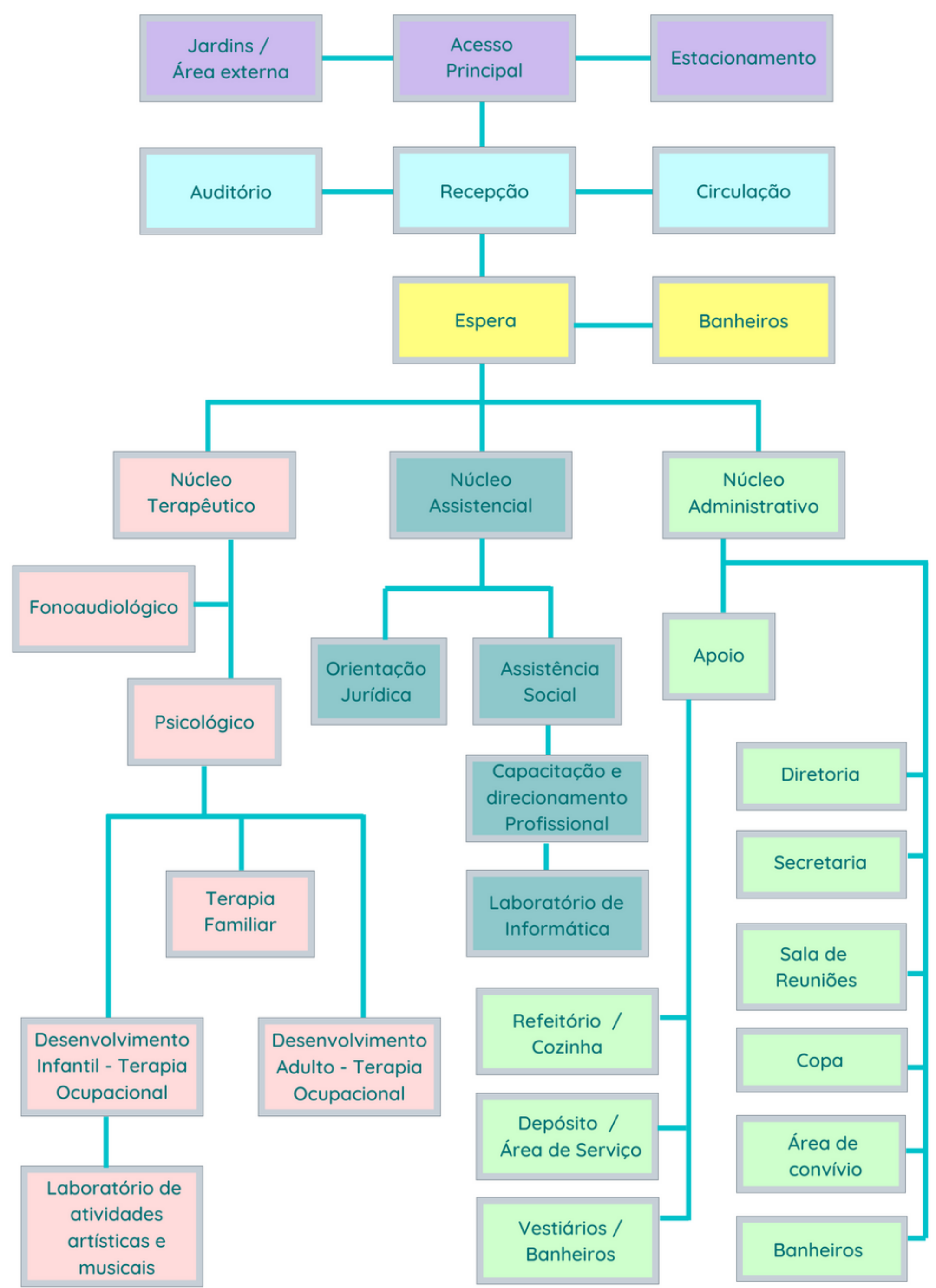

áreas externas

áreas de uso comum

Espera assistidos

Núcleo Assistencial

Núcleo Terapêutico

Núcleo Administrativo 


\section{LOCALIZAÇÃO}

(c)

VILA VALQUEIRE

Parque Shopping Sulacap JARDIM SULACAP

Eatr. do Catonho

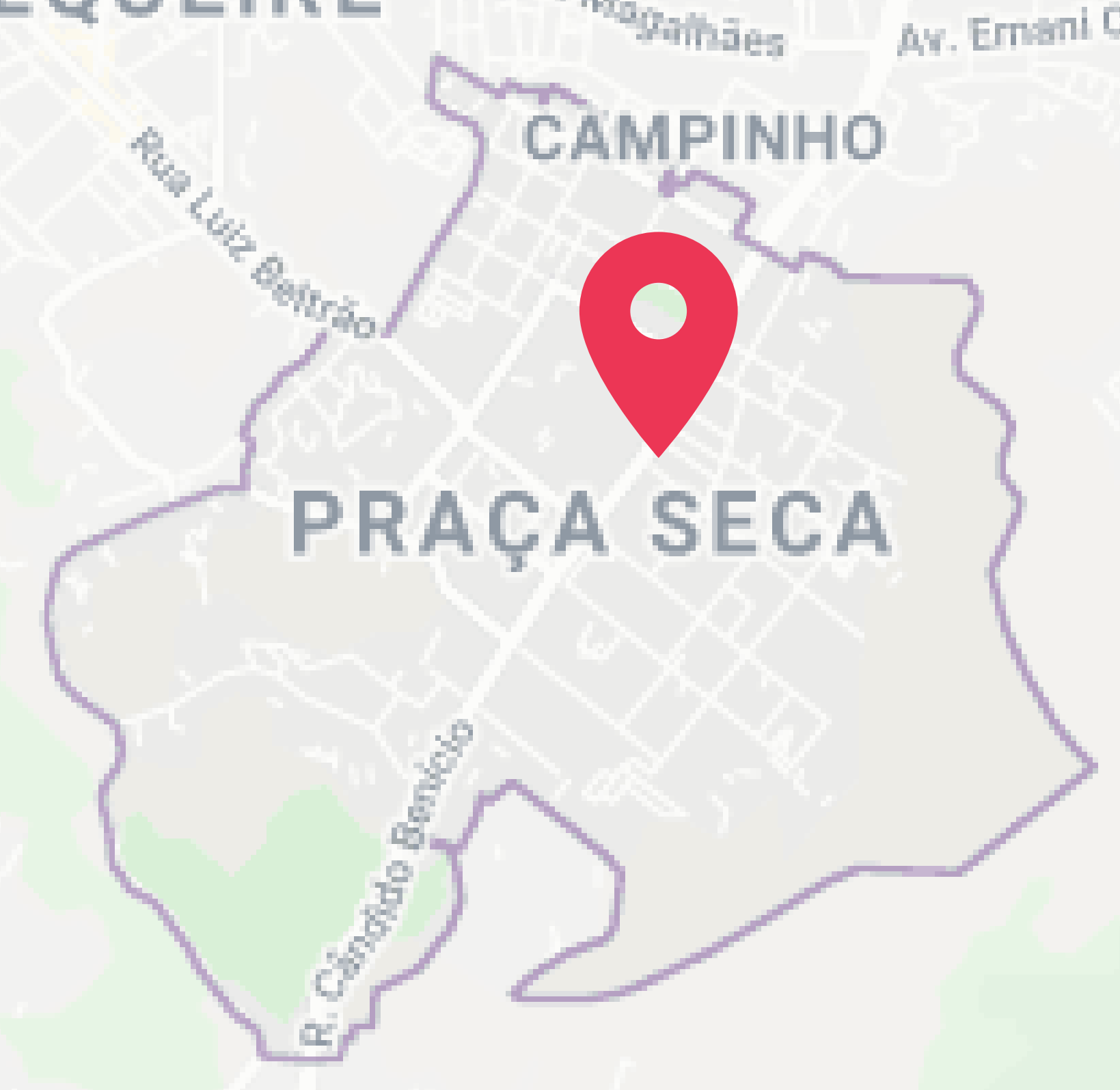

CASCADURA
田
[9.

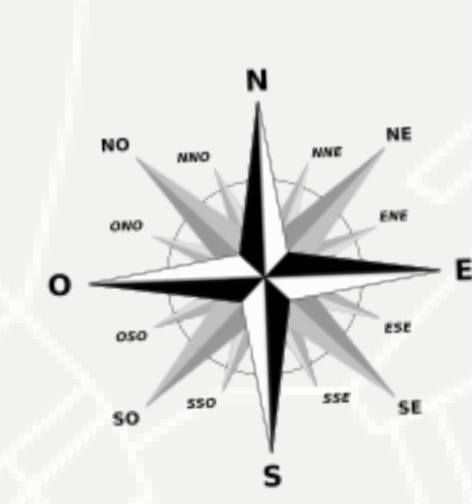

ABOLI

D

PIEDADE

ENCANTA

TANQUE 

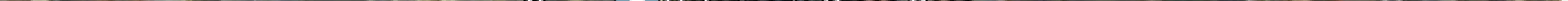


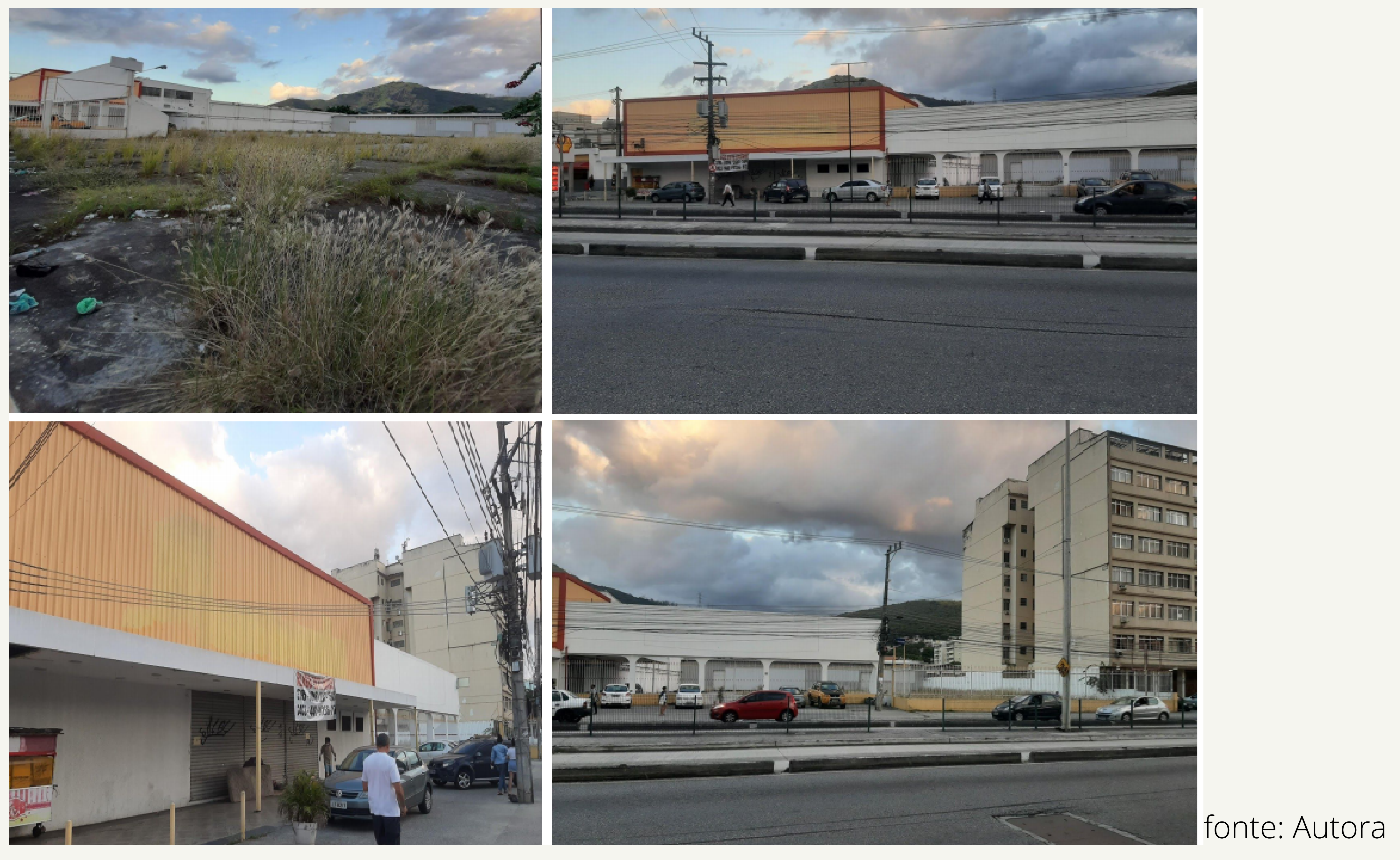




\begin{tabular}{|lr|}
\hline QUADRO DE AREAS: \\
\hline RA: XVI & \\
AP: 4 & \\
ZONA: ZR-3 & \\
I.A.T. $=3$ & \\
AREA DO TERRENO & $3.084,59 \mathrm{~m} 2$ \\
AREA EDIFICADA BLOCO 01 & $288,00 \mathrm{~m} 2$ \\
AREA EDIFICADA BLOCO 02 & $432,00 \mathrm{~m} 2$ \\
ÁREA EDIFICADA BLOCO 03 & $192,00 \mathrm{~m} 2$ \\
AREA EDIFICADA BLOCO 04 & $368,00 \mathrm{~m} 2$ \\
ATC. & $1.280,00 \mathrm{~m} 2$ \\
ATE PERMITIDA & $9.253,77 \mathrm{~m} 2$ \\
ATE PROJETADA & $1.280,00 \mathrm{~m} 2$ \\
TAXA DE OCUPAÇAO PERMITIDA & $70 \%$ \\
TAXA DE OCUPAÇÃO PROJETADA & $41,50 \%$ \\
AFASTAMENTO FRONTAL MINIMO PERMITIDO & $3,00 \mathrm{~m}$ \\
AFASTAMENTO FRONTAL PROJETADO & $6,00 \mathrm{~m}$ \\
GABARITO PERMITIDO & 6 PAVIMENTOS \\
GABARITO PROJETADO & 1 PAVIMENTO \\
TAXA DE PERMEBILIDADE PERMITIDA & $15 \%$ \\
TAXA DE PERMEABILIDADE PROJETADA & $17,60 \%$ \\
N* DE VAGAS PERMITIDA & 1 VAGA $200 \mathrm{~m} 2$ AREA UTIL \\
N* DE VAGAS PROJETADA & 08 VAGAS \\
\hline
\end{tabular}




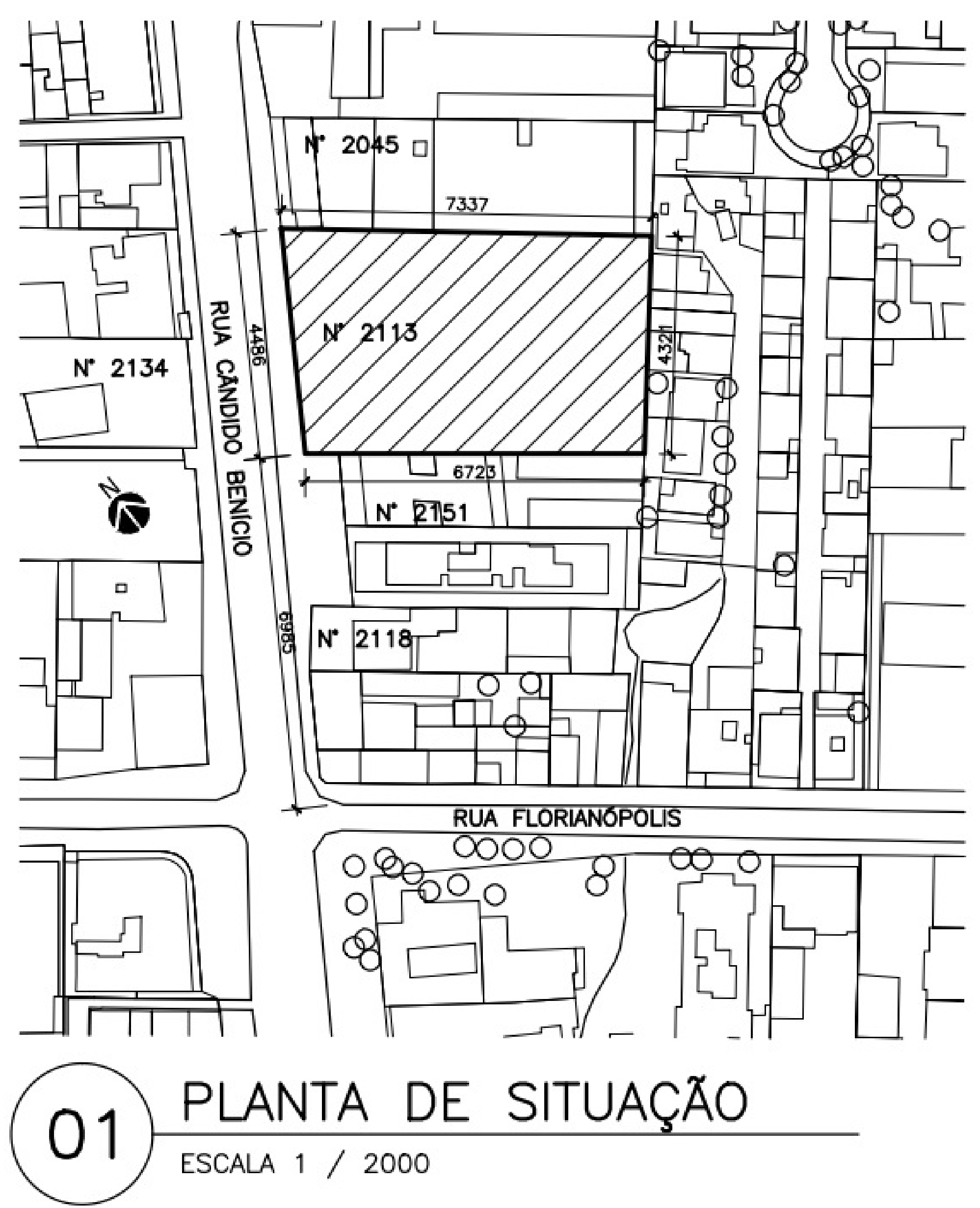




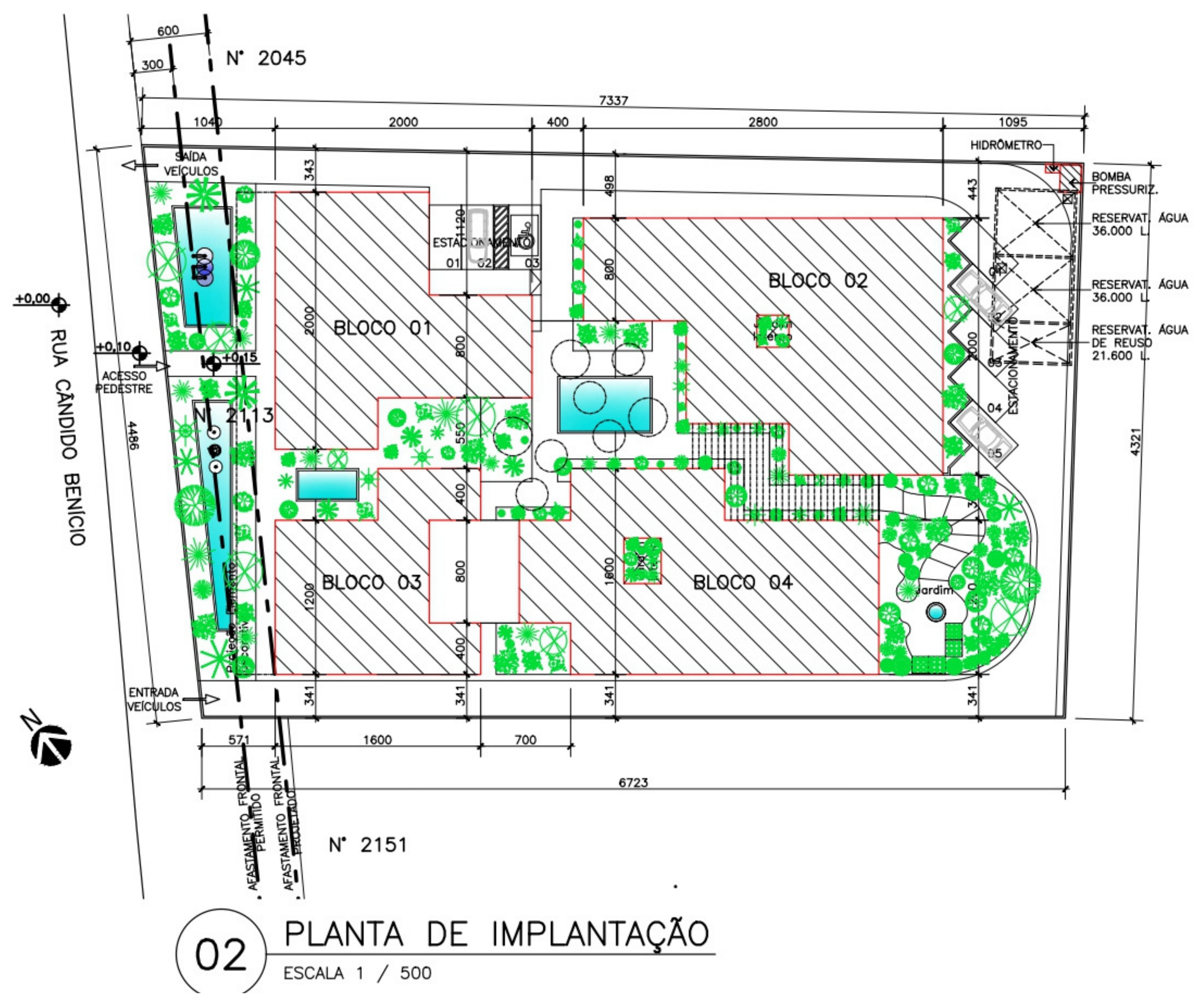




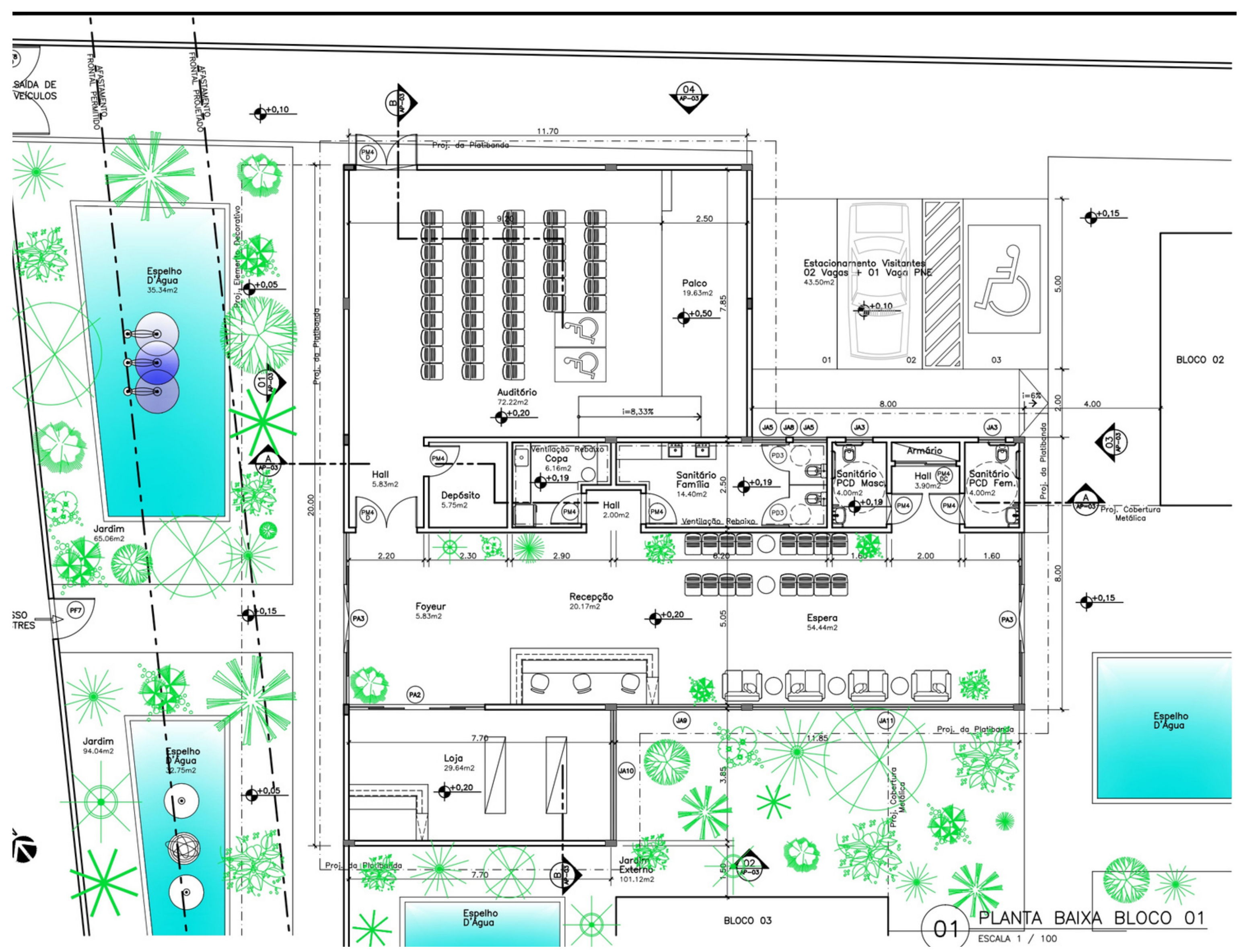




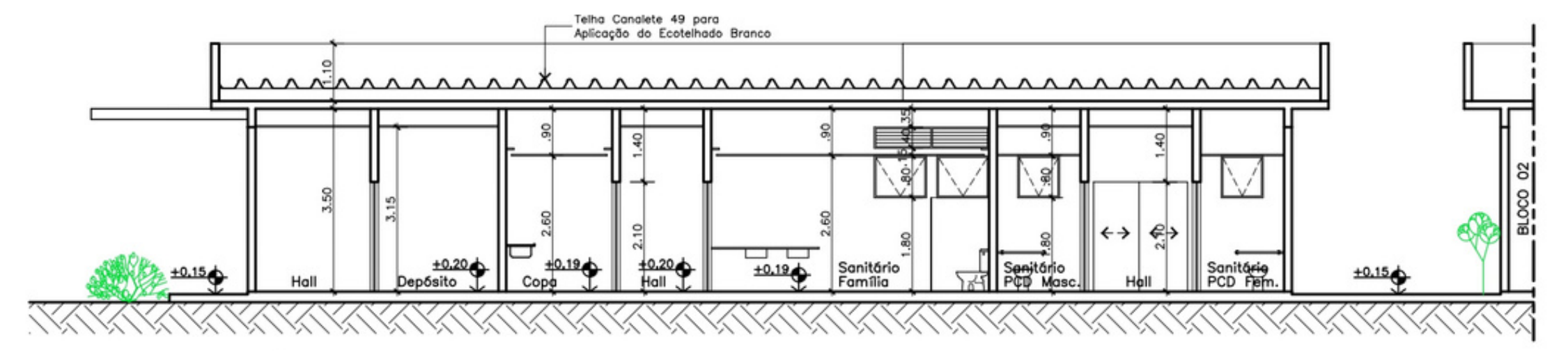

(01) $\frac{\text { CORTE A }}{\text { ESCAA } 1 / 100}$

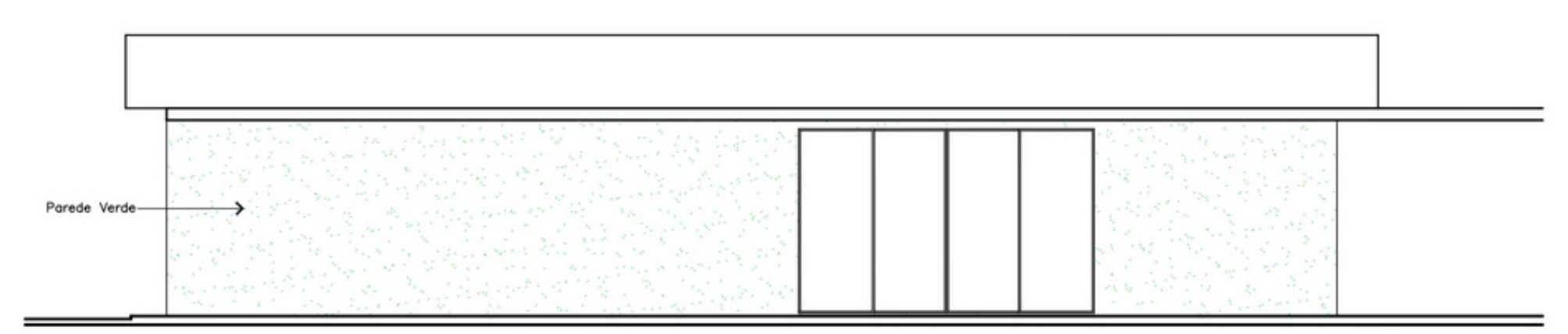

(03) FACHADA 01

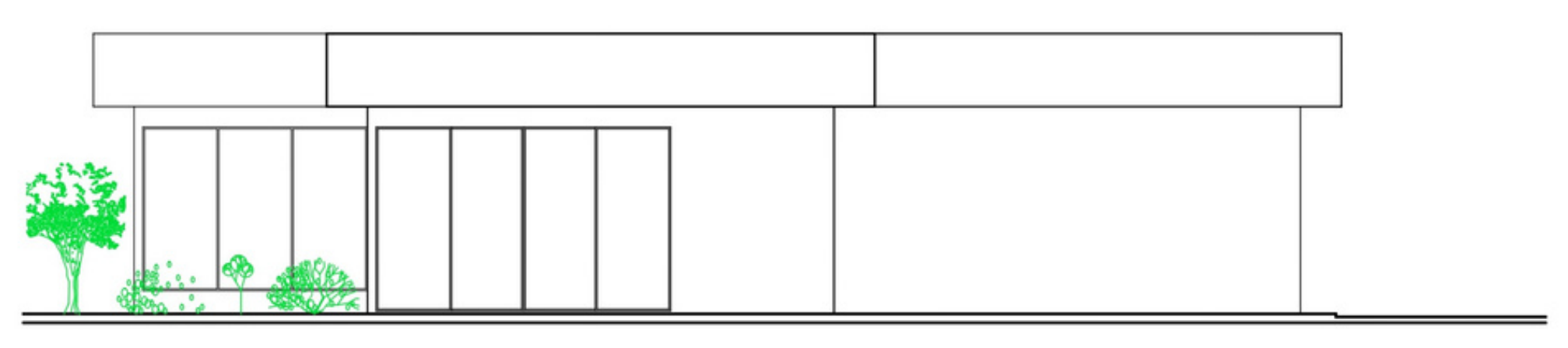

(05) FACHADA 03

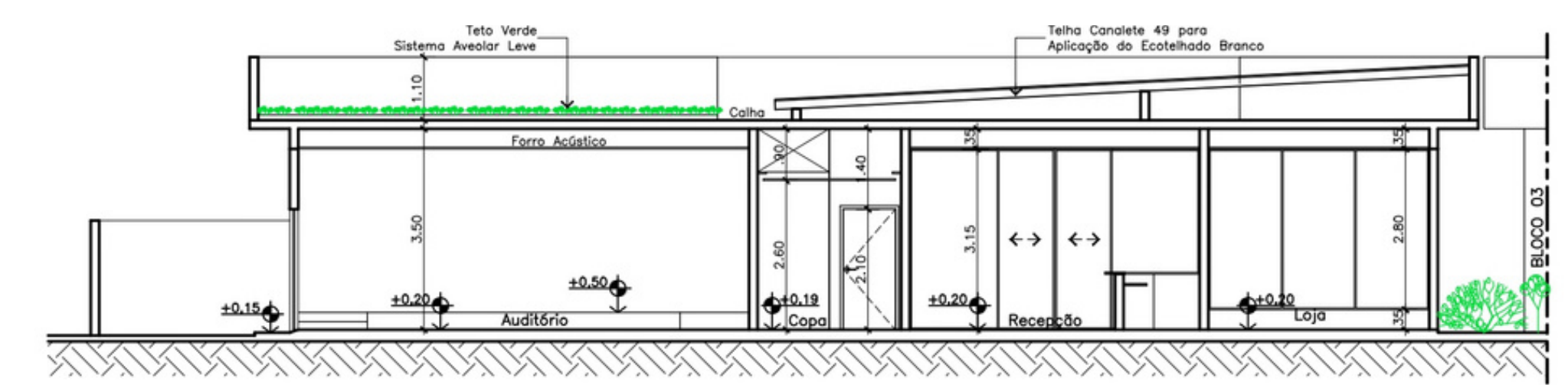

(02) CORTE B

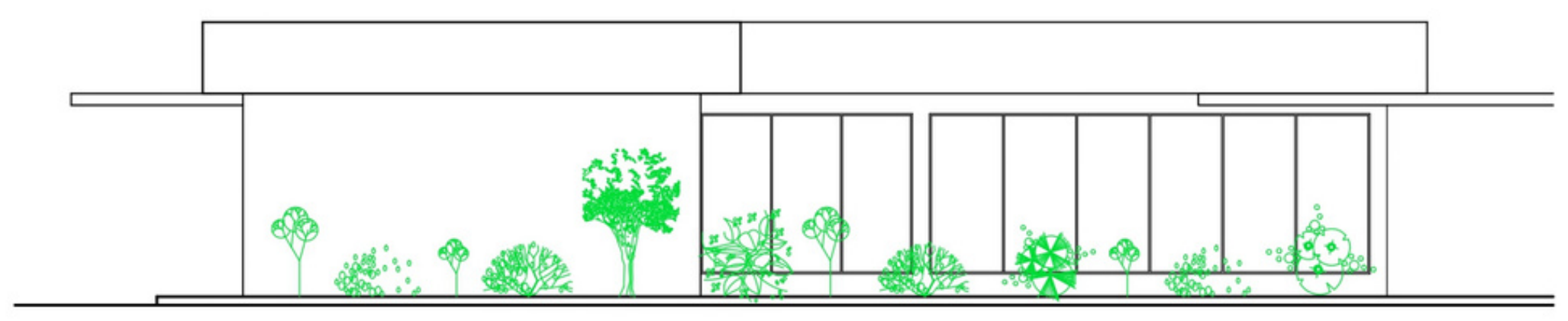

04 FACHADA 02

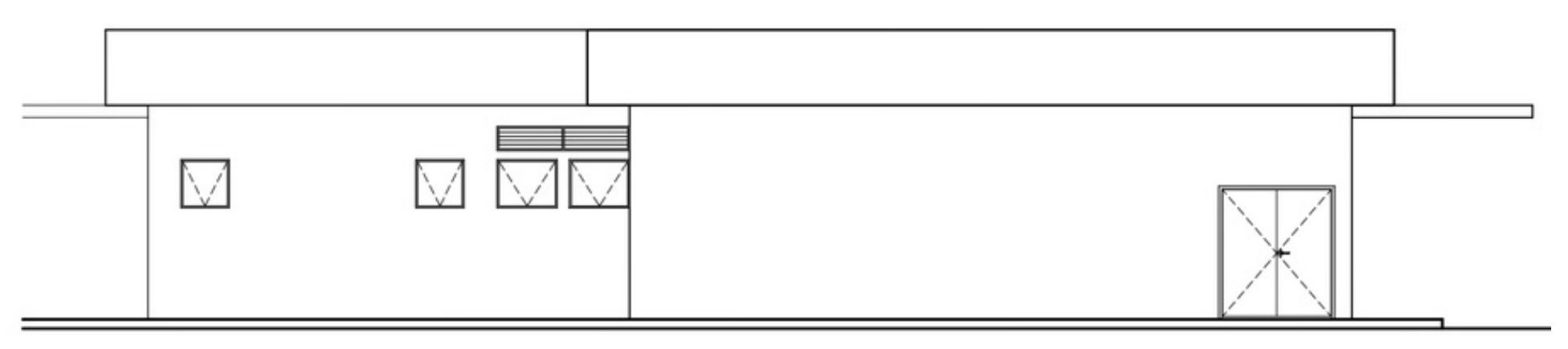

(06) $\frac{\text { FACHADA } 04}{\mathrm{ESCAA} 1 / 100}$ 


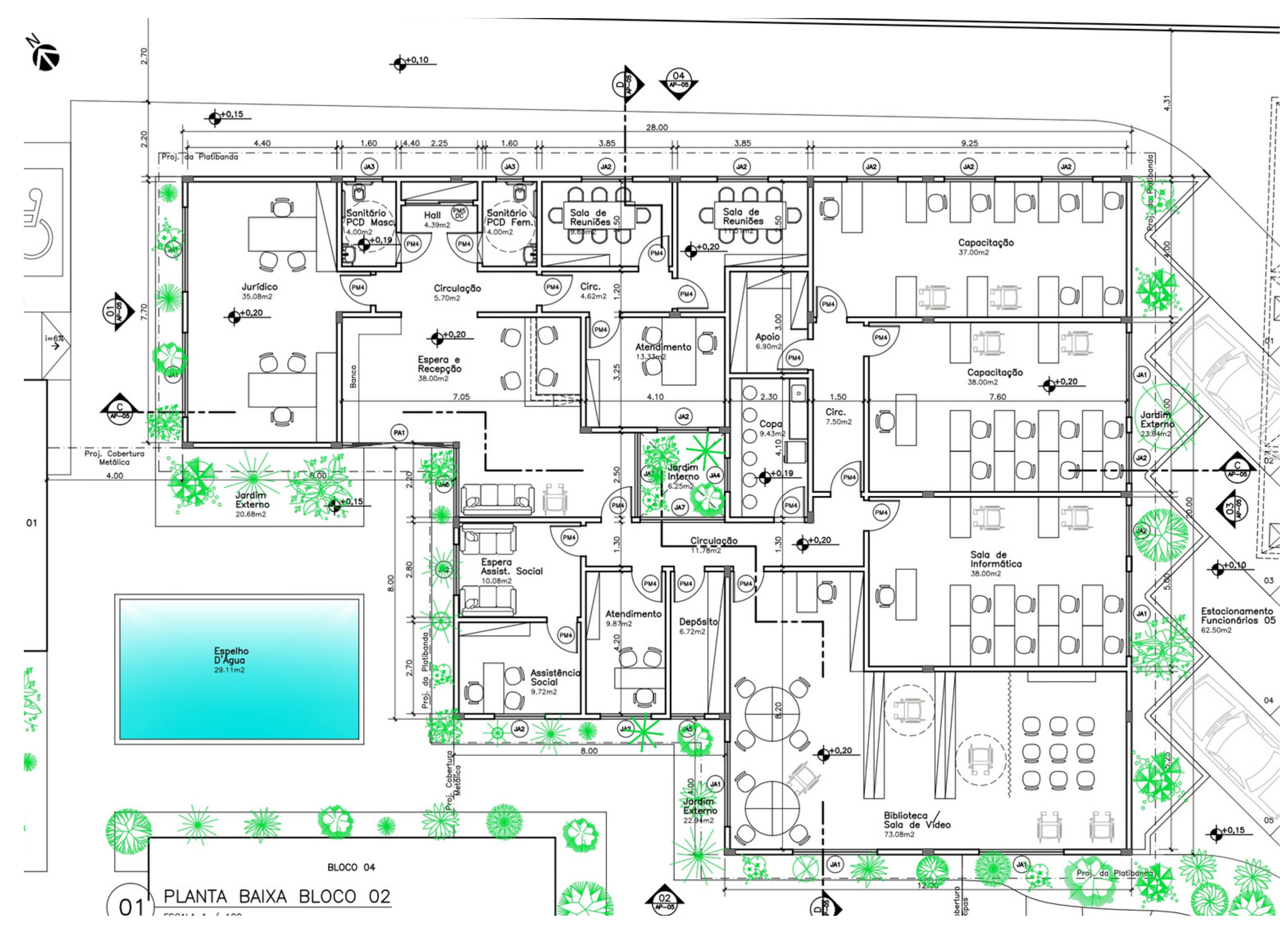




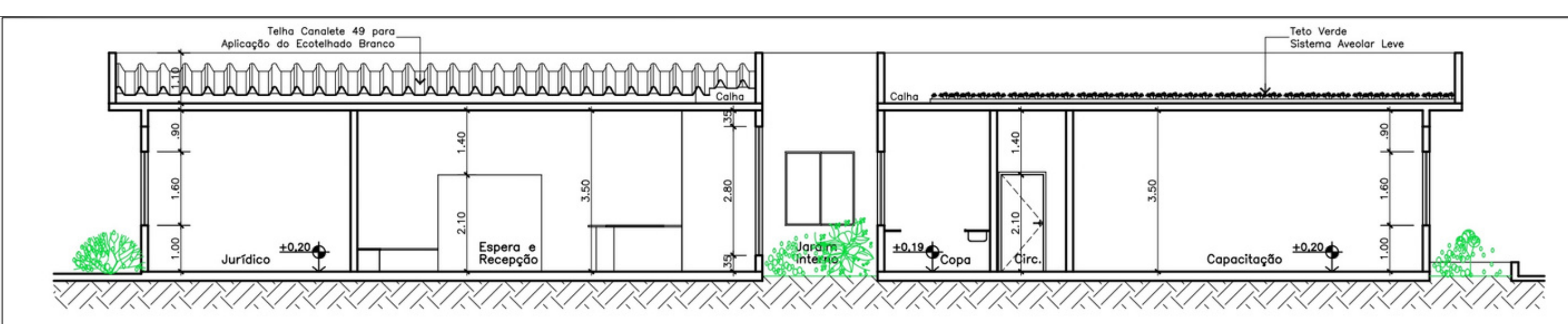

(01) CORTE C

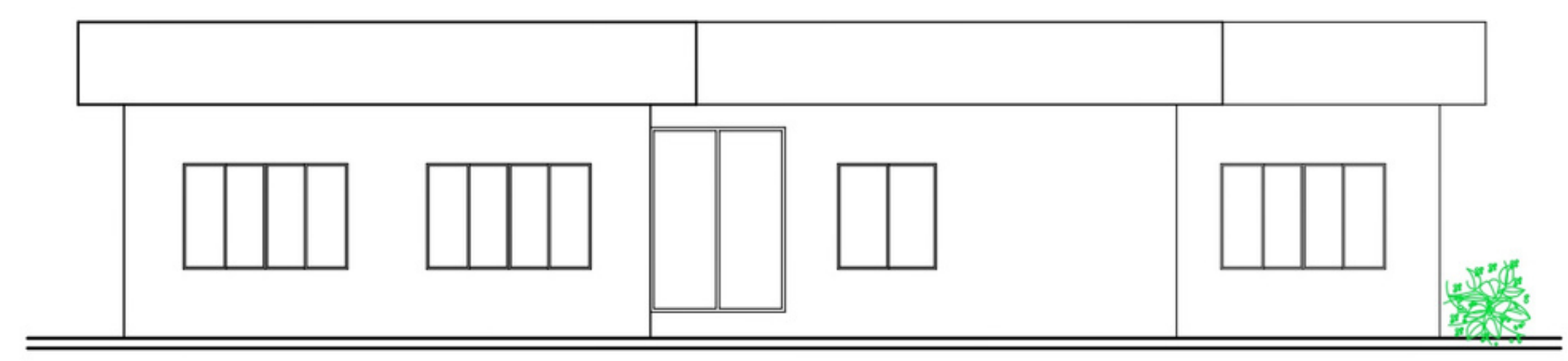

(03) FACHADA 05

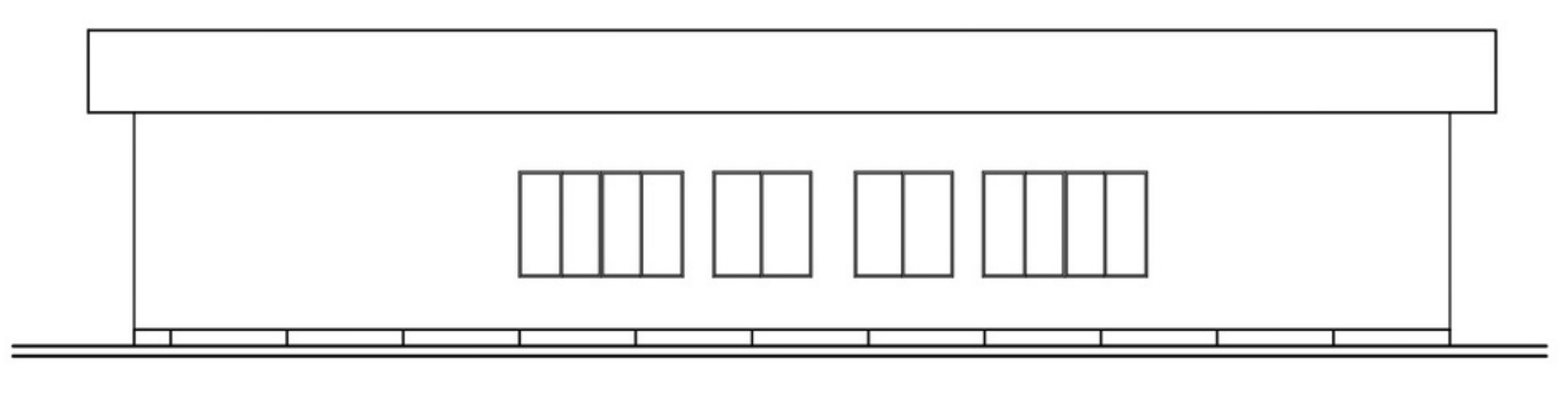

(05) FACHADA 07

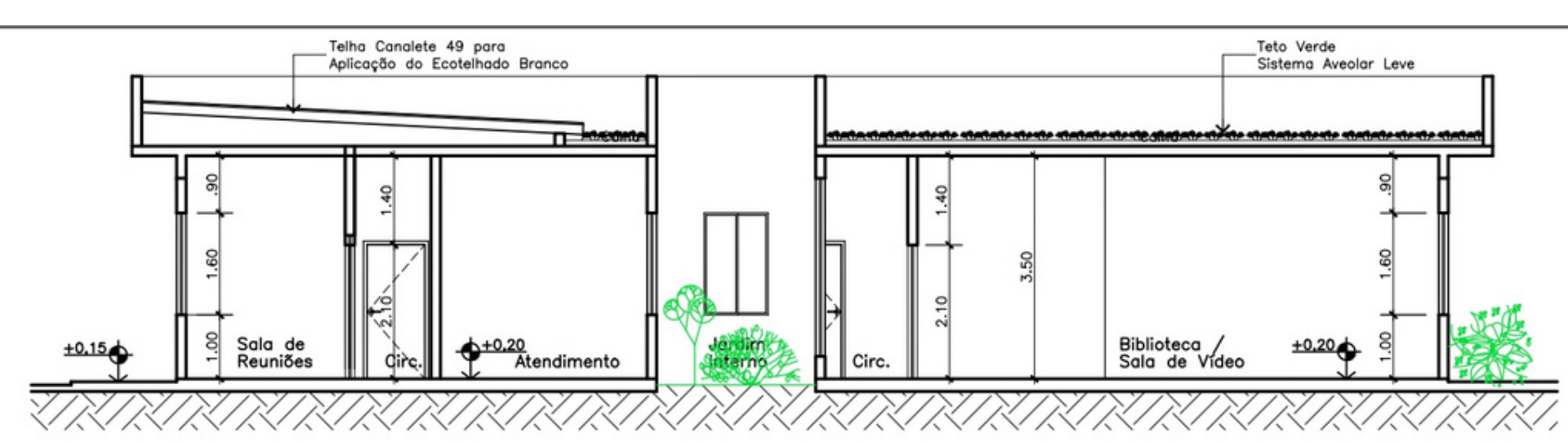

(02) CORTE D

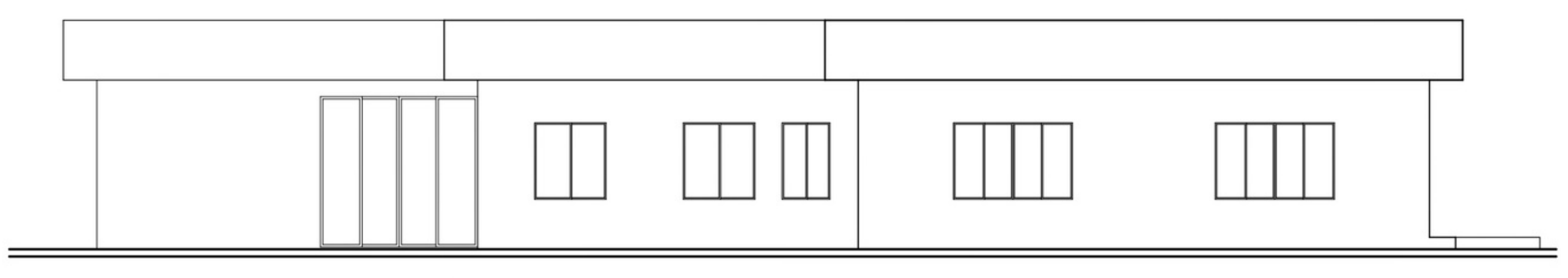

(04) FACHADA O6

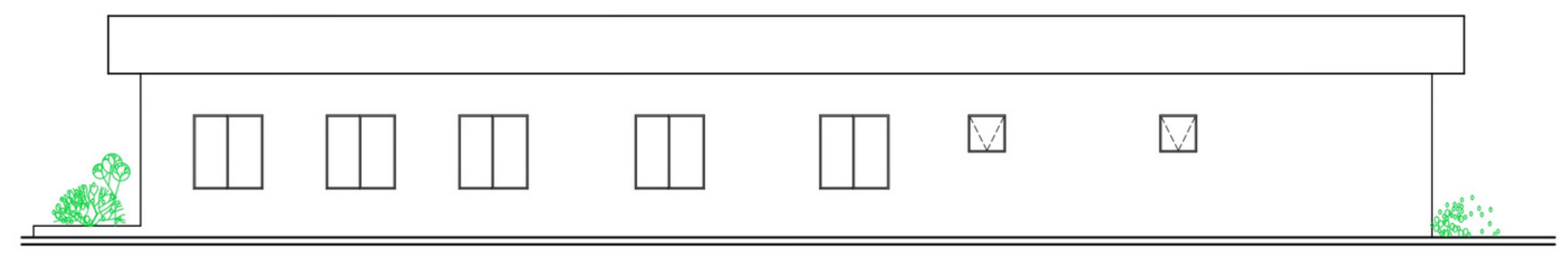

(06) $\frac{\text { FACHADA } 08}{\text { ESCALA } 1 / 100}$ 


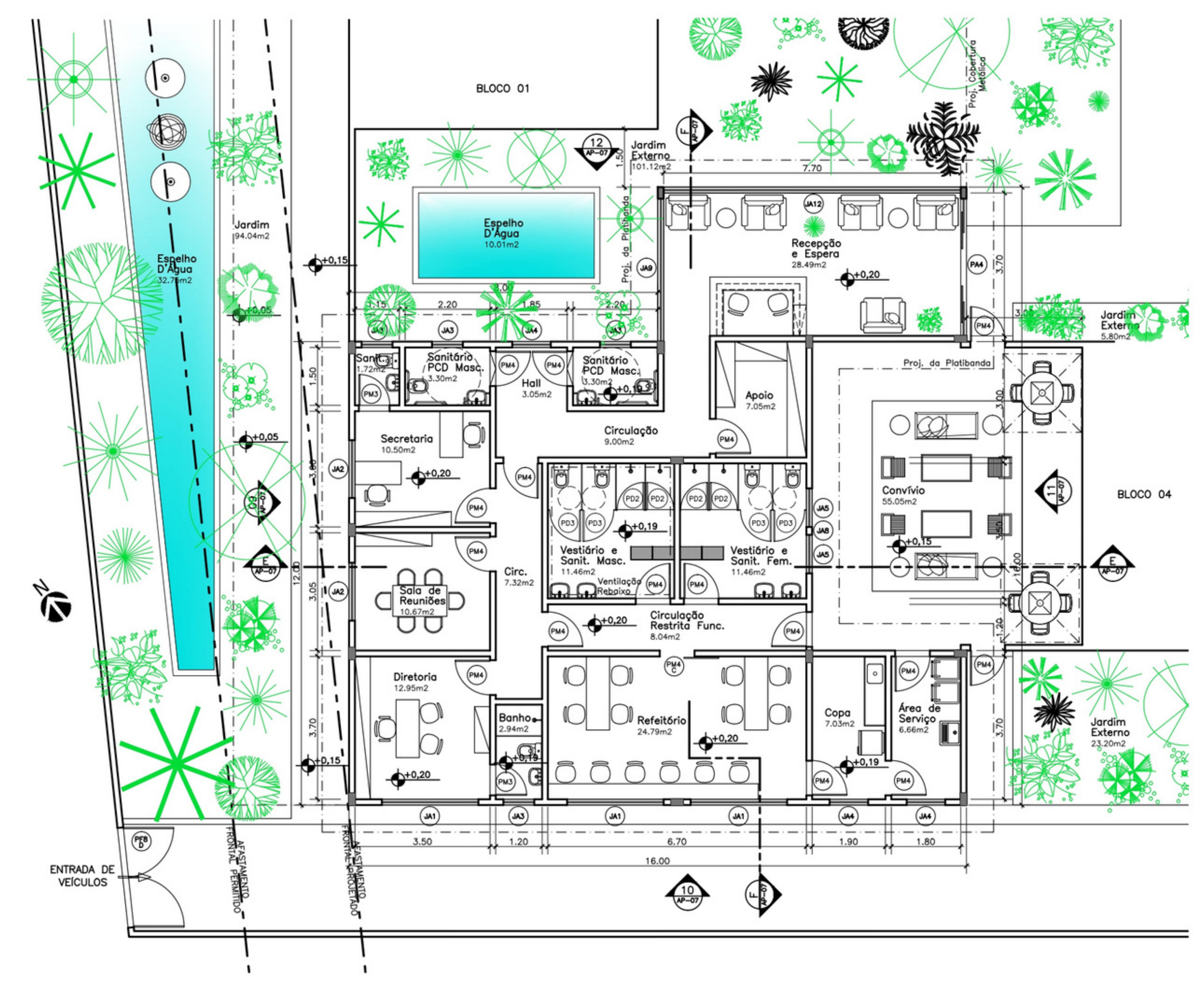

(01) PLANTA BAIXA BLOCO 03 


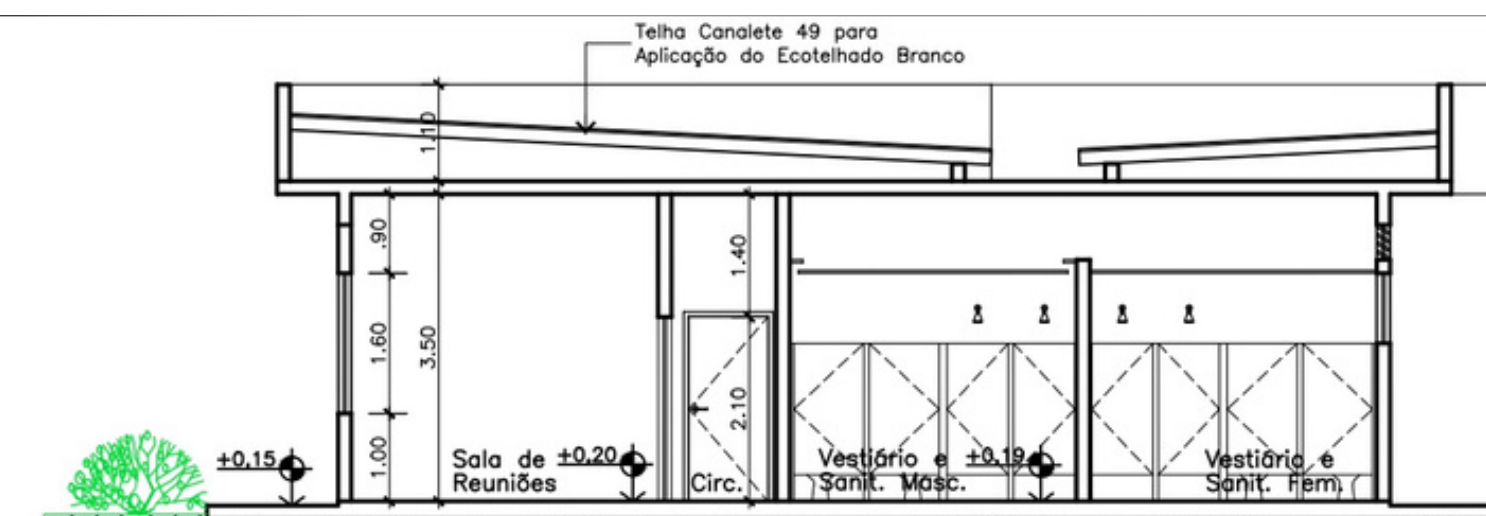

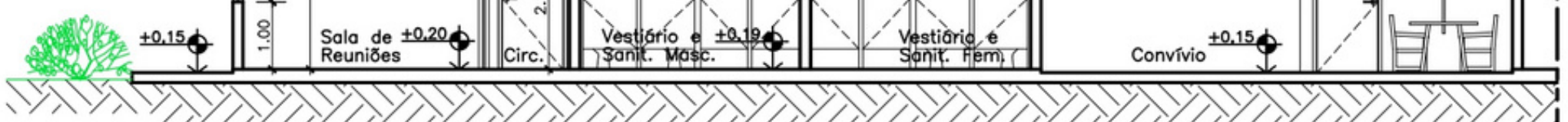

$$
01 \text { CORTE E }
$$

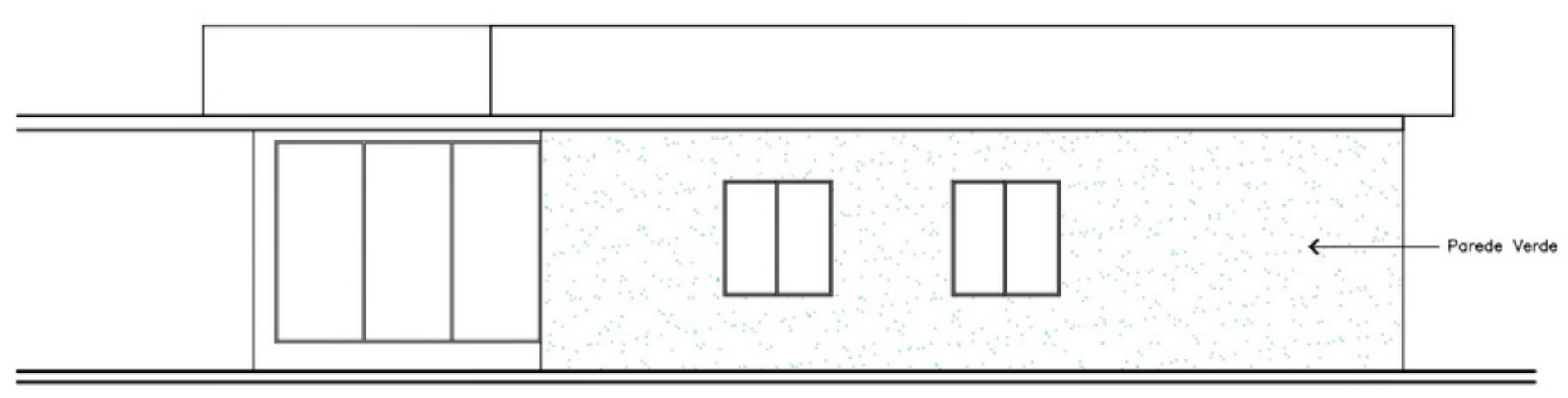

03 FACHADA O9

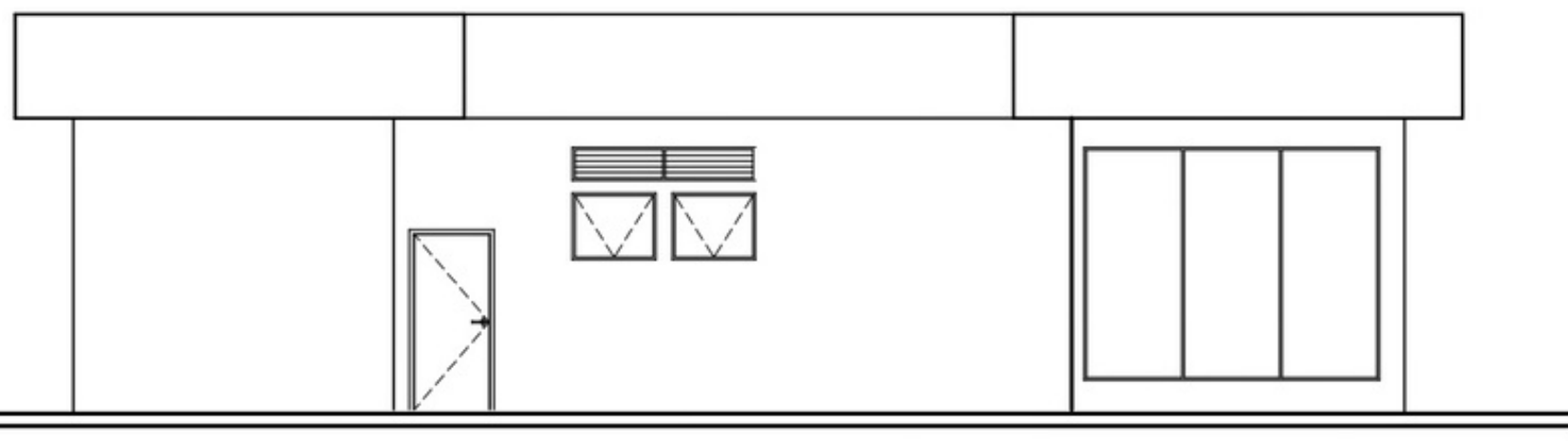

(05) FACHADA 11

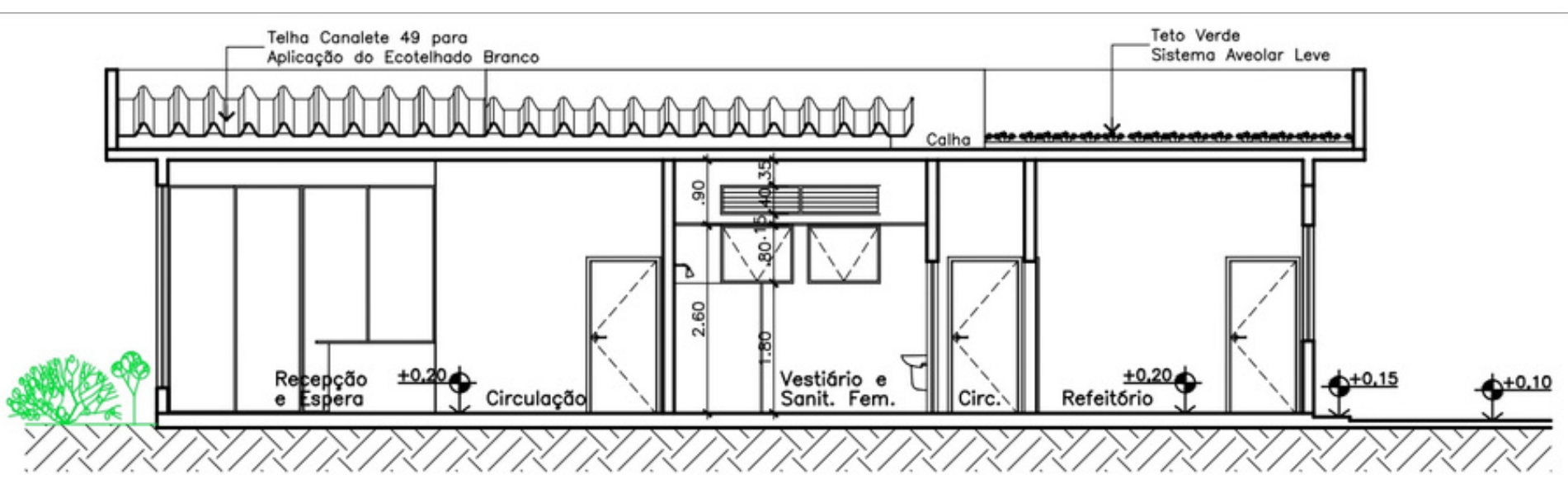

(02) CORTE F

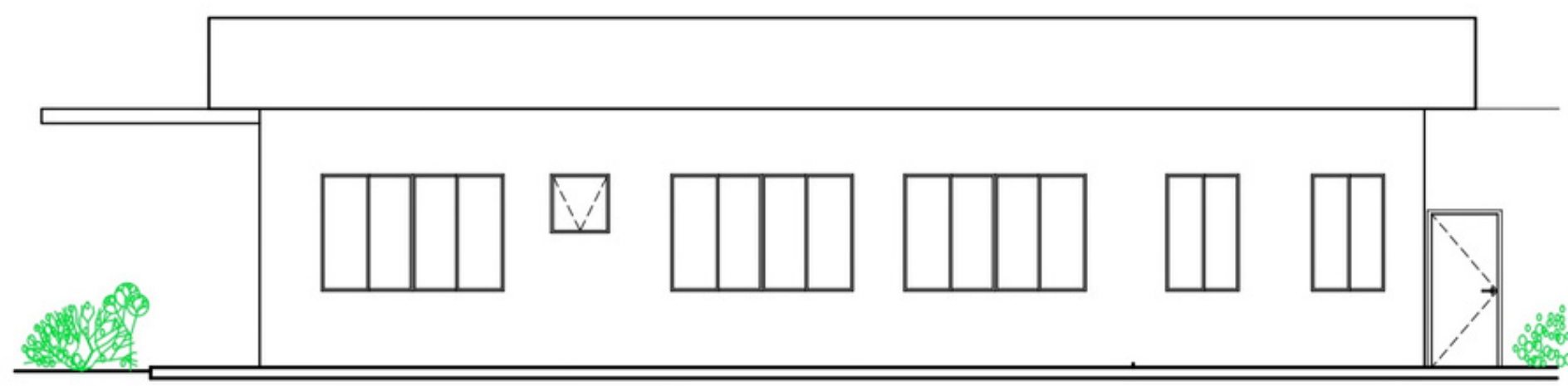

04 FACHADA 10

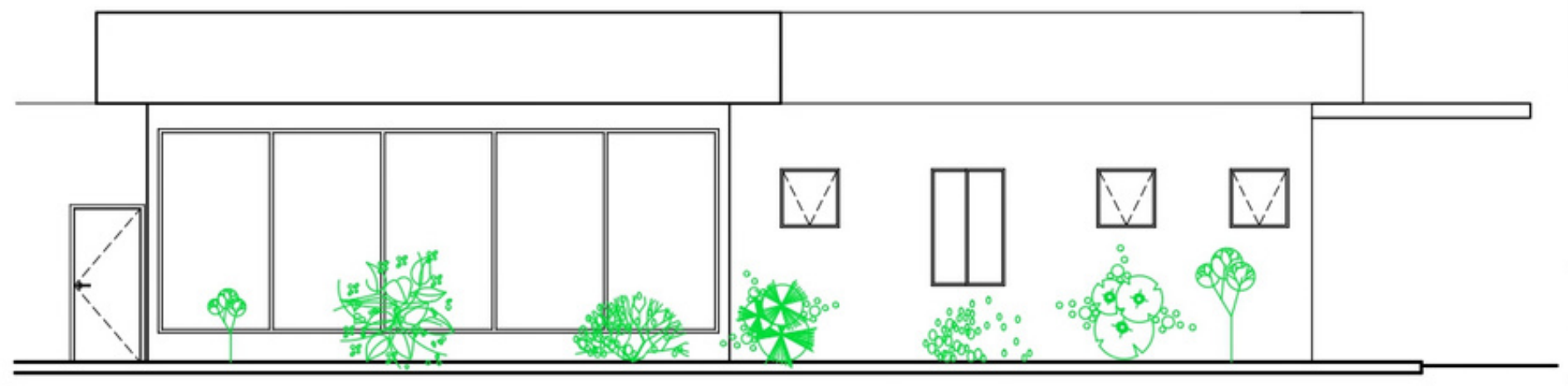

(06) FACHADA 12 


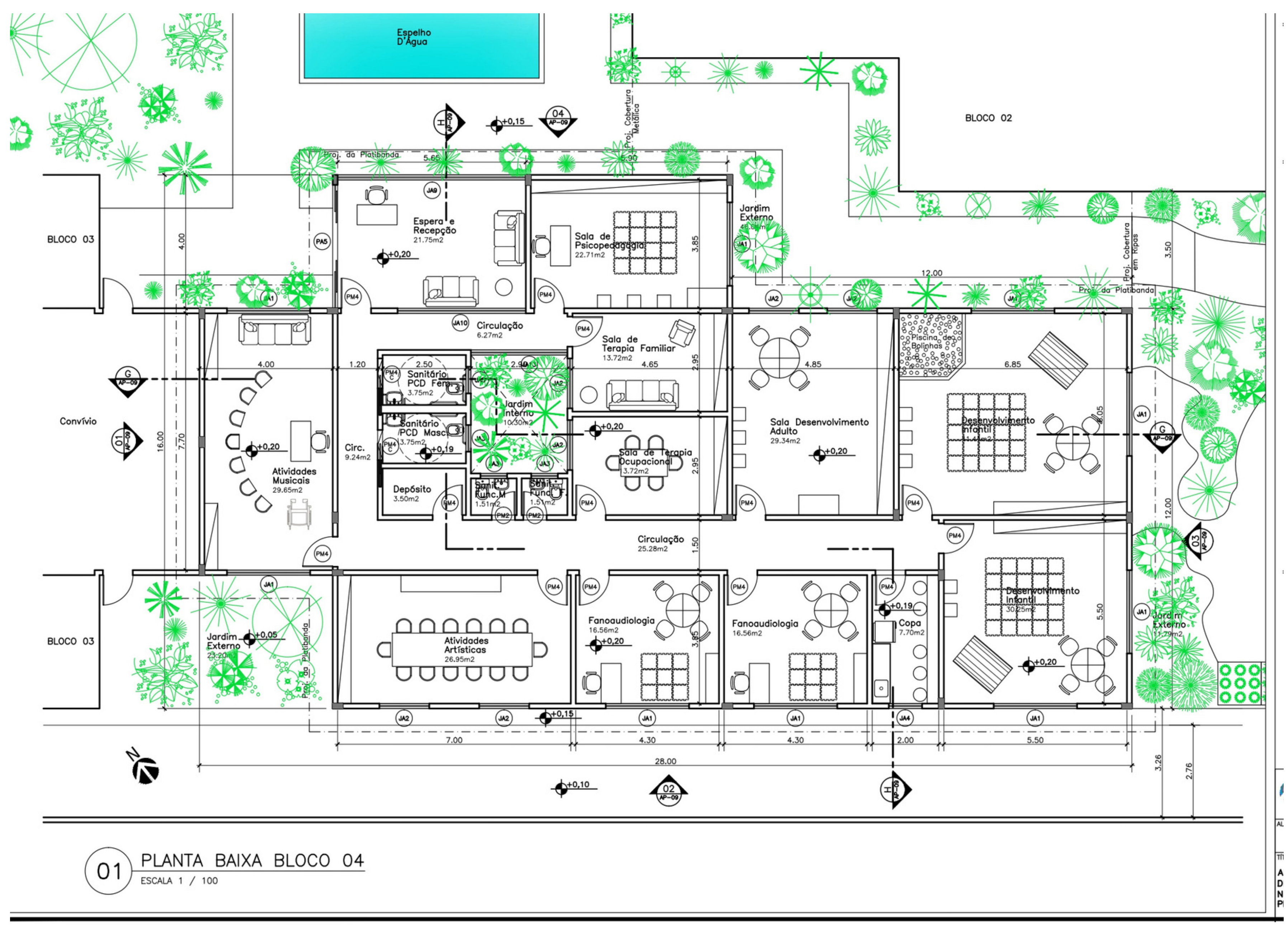




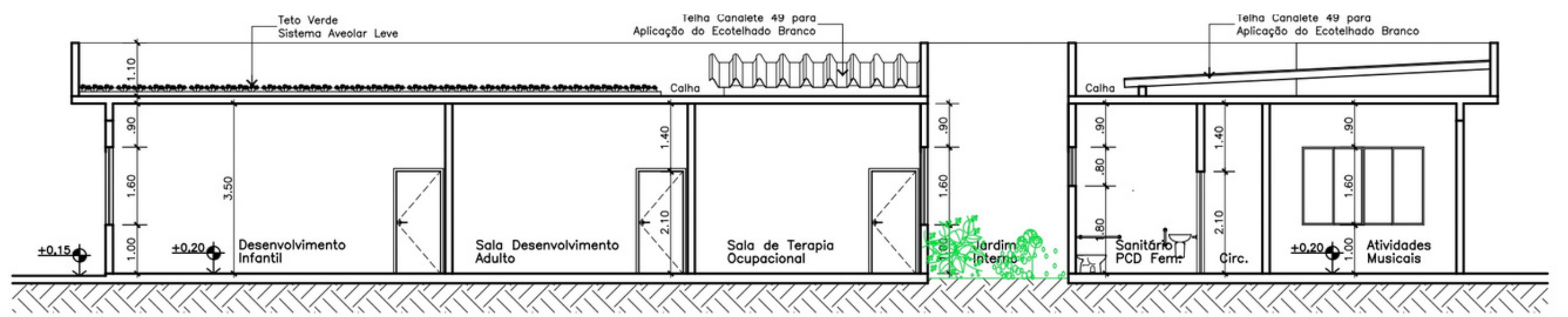

(01) CORTE G

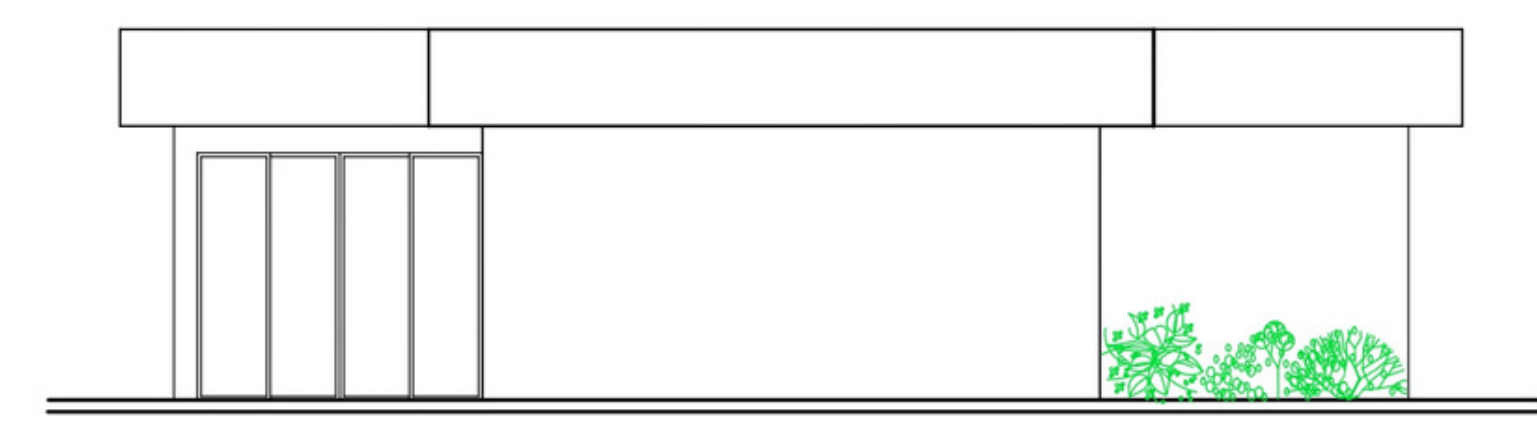

(03) FACHADA 13

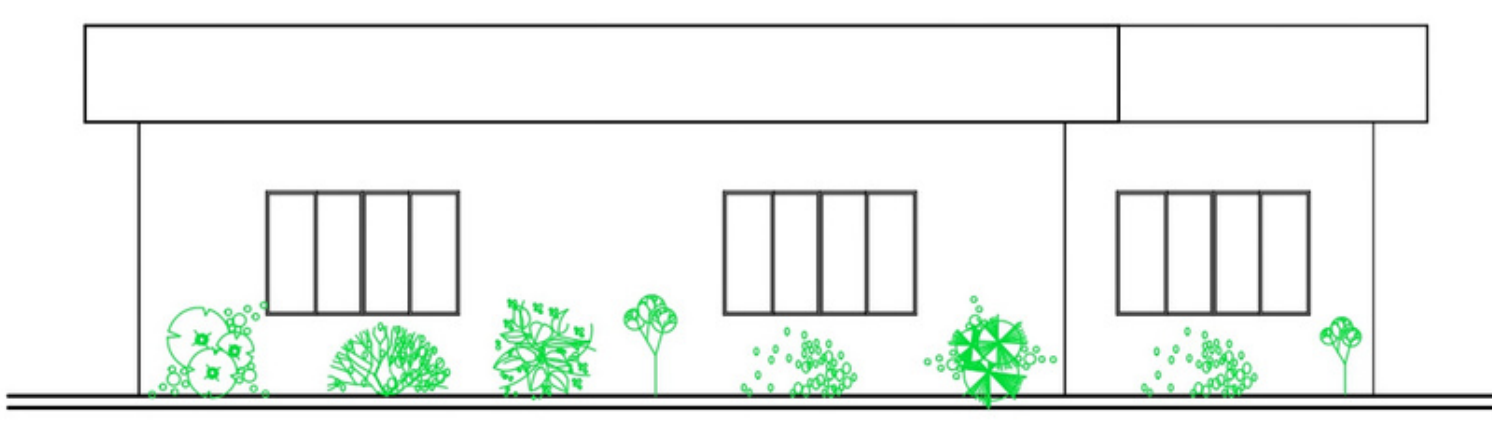

(05) FACHADA 15

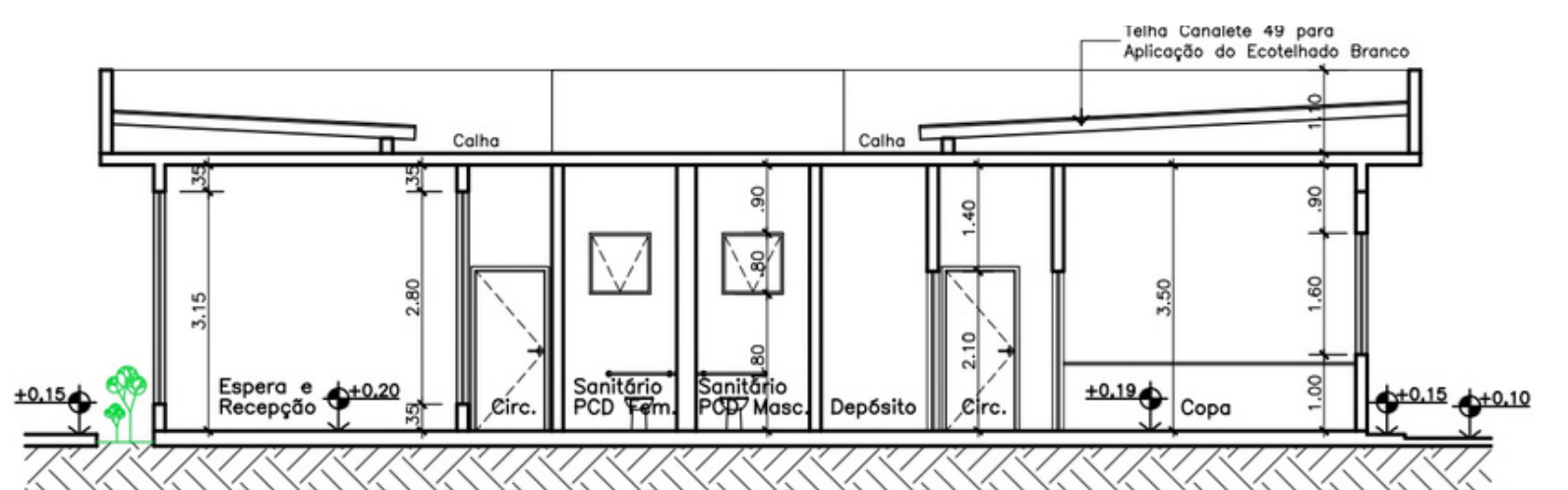

(02) CORTE H

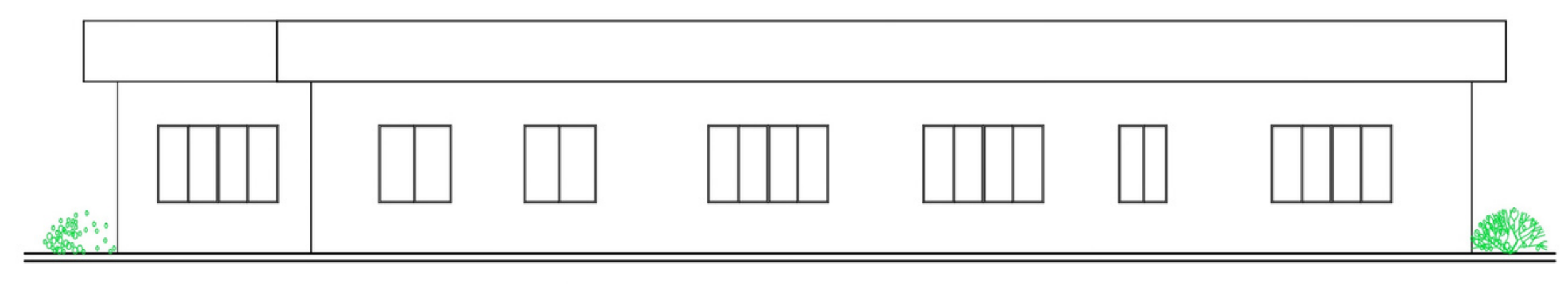

(04) $\mathrm{FACHADA} 14$

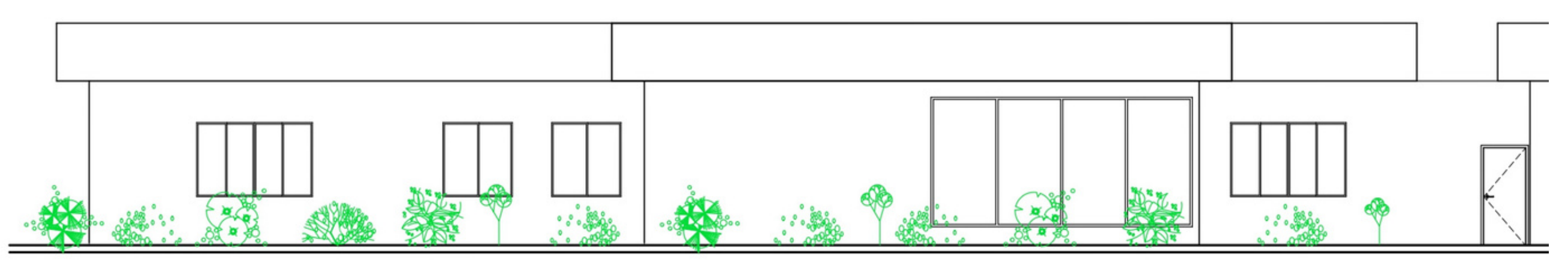

(06) FACHADA 16 


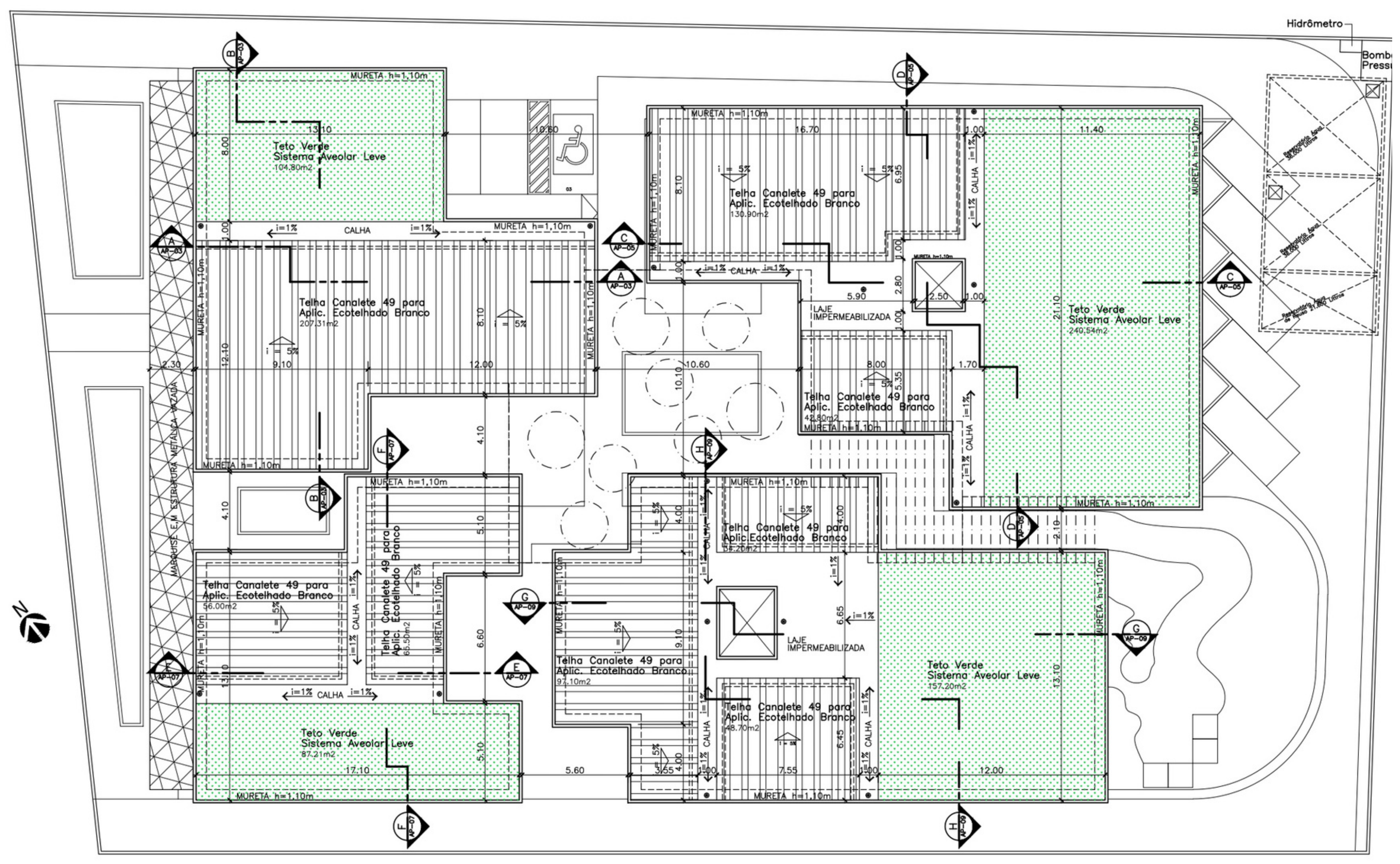

(01) PLANTA BAIXA TELHADO GERAL 


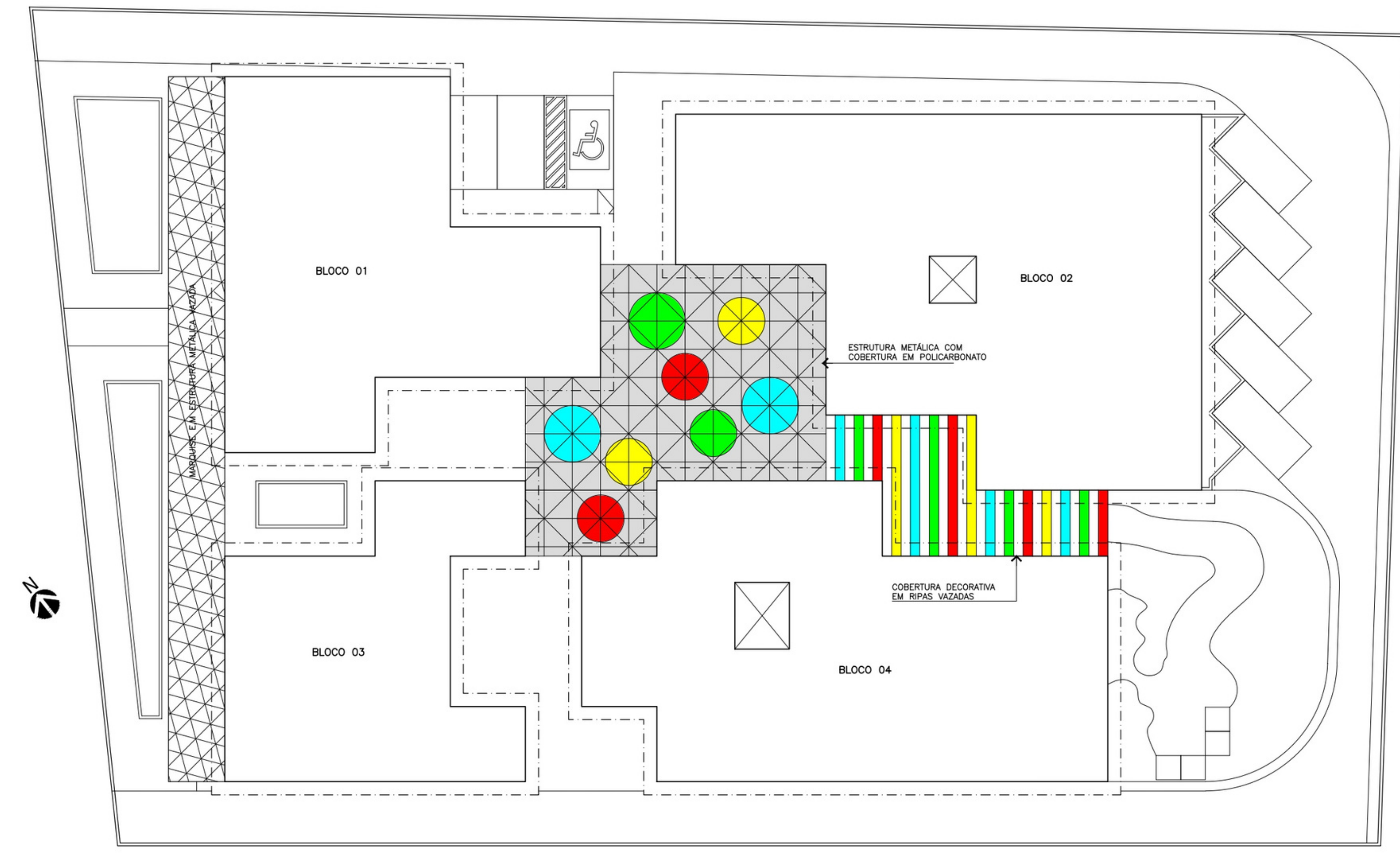

(01) PLANTA DA COBERTURA METÁLICA 


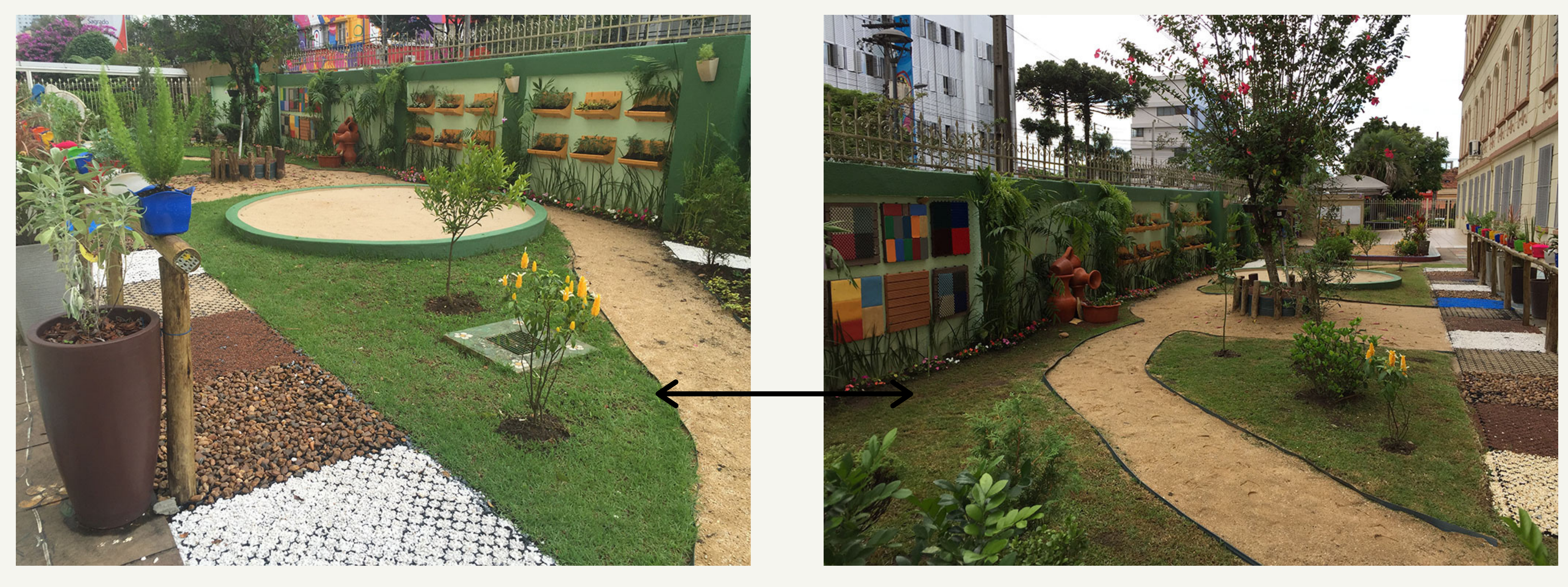

Jardim Sensorial 


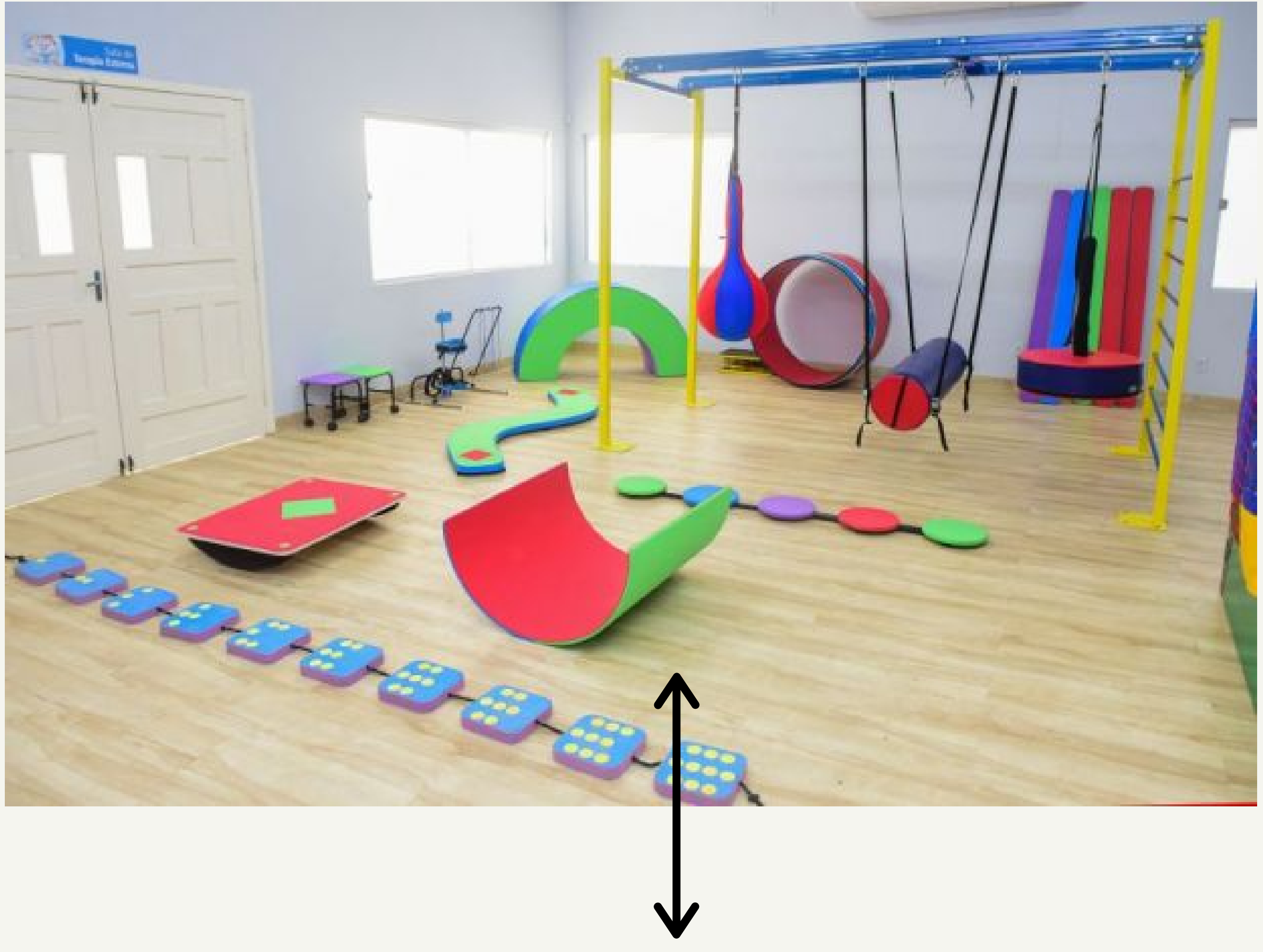

Salas de desenvolvimento

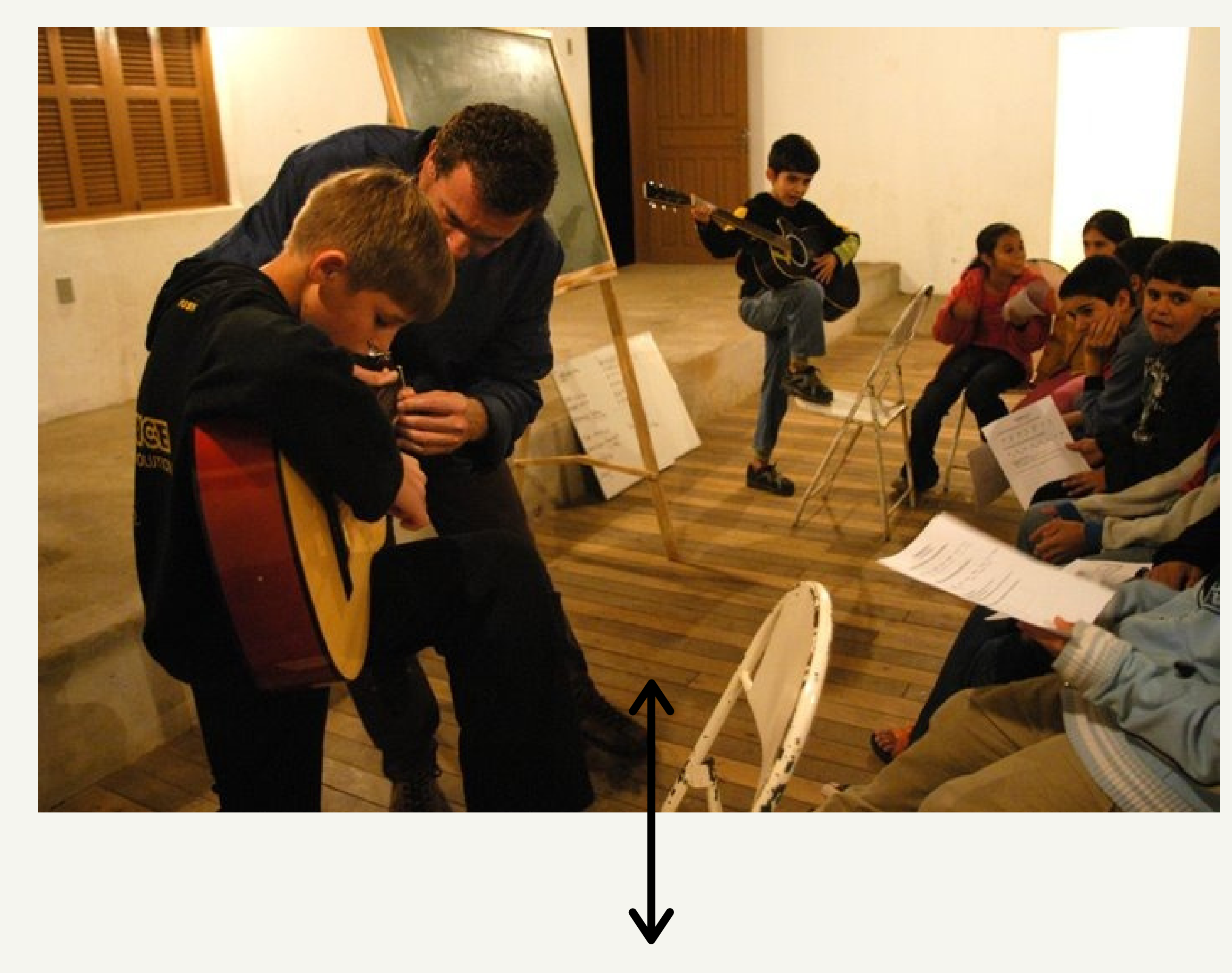

Salas de música 
Salas de Psicopedagogia

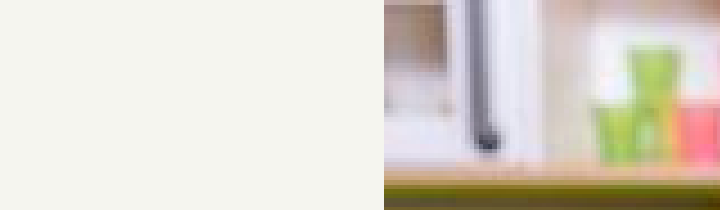




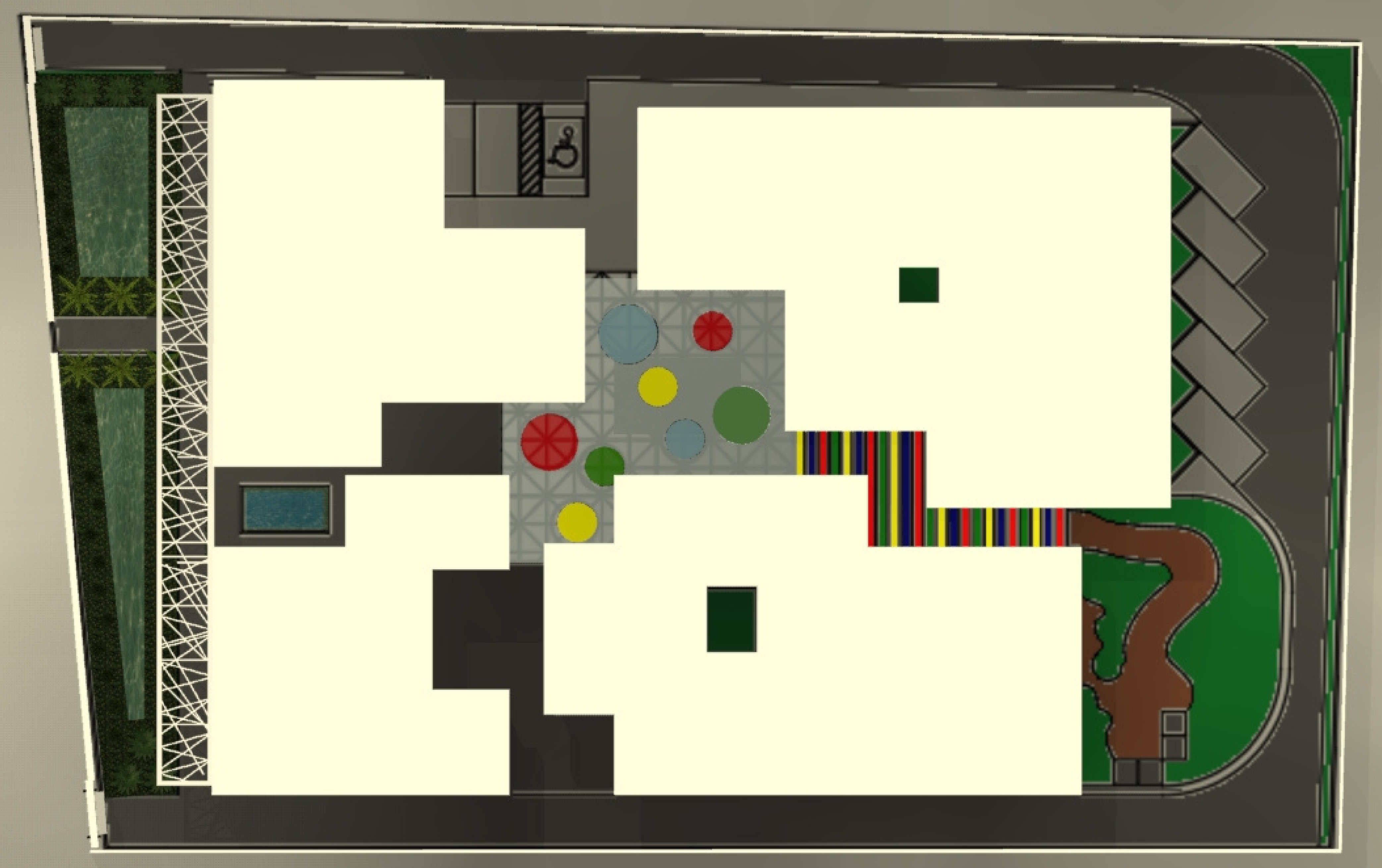



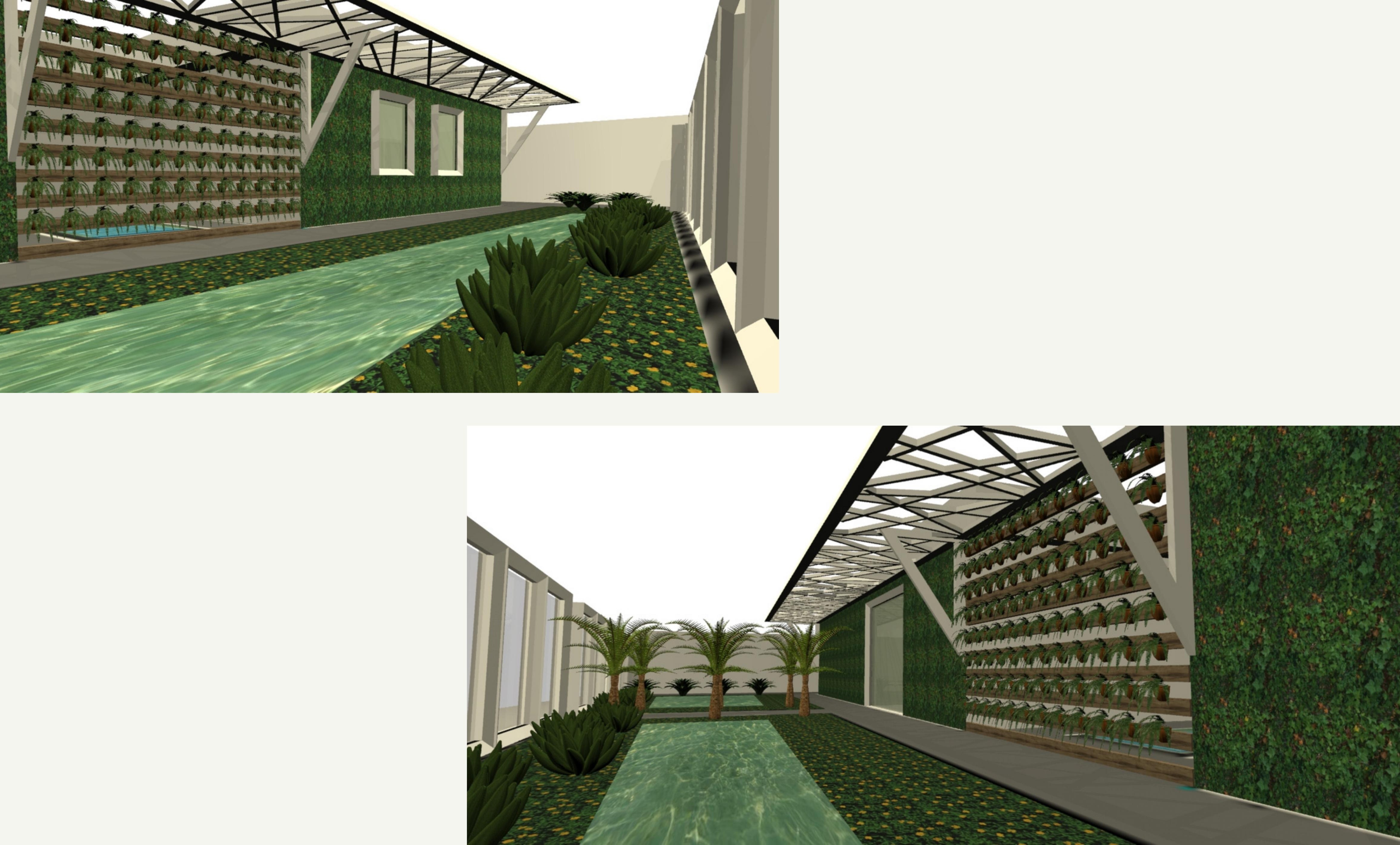


\section{CONSIDERAÇÕES FINAIS:}

É um grande desafio a ser superado: projetar para o autista de forma a facilitar a ambientação com estímulo positivo sendo prioridade.

Como acompanhado, diversos recursos foram adotados para a criação de um ambiente acolhedor e cognitivamente acessível.

As palavras essenciais neste projeto são: Objetividade e Simplicidade, para mudar o cenário do atendimento ao autista oferecido hoje pelas entidades públicas no Rio de Janeiro, que é insuficiente e ineficiente, carecendo de novas propostas e locais adequados para a disponibilização desses serviços.

A integração multidisciplinar oferecida pelo Centro de Apoio e Desenvolvimento ao Autista, é inovadora e visa atender e oferecer acolhimento às famílias e possibilitando a inclusão do autista na sociedade de forma digna, com olhar voltado para seu futuro. 
FIM obRIgADA!

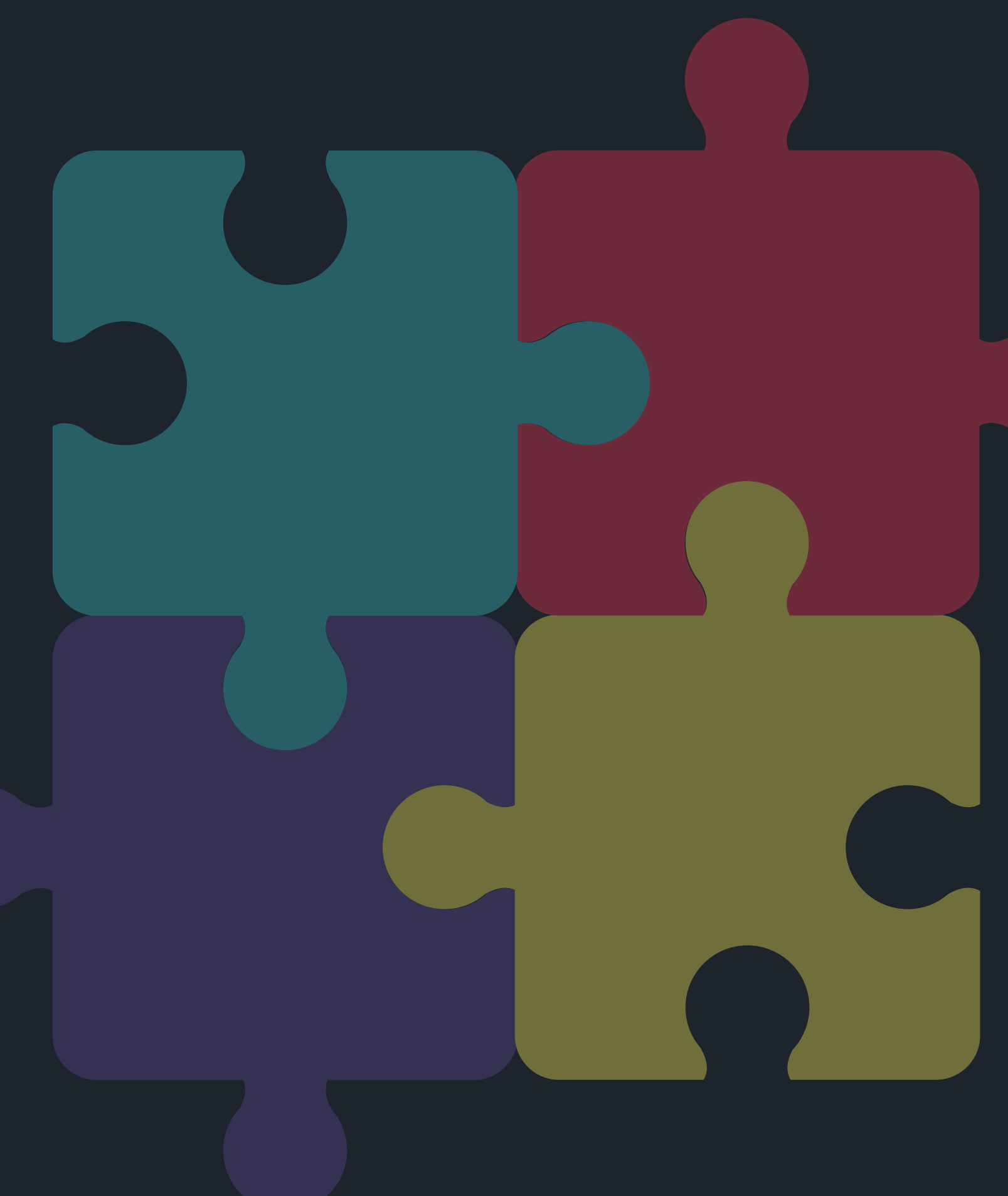

